\title{
Energy Consumption Analysis of a Large Building at Memorial University
}

\author{
Almahdi Abdo-Allah (D), ${ }^{1}$ M. Tariq Iqbal $\left(\mathbb{D},{ }^{1}\right.$ and Kevin Pope ${ }^{2}$ \\ ${ }^{1}$ Department of Electrical and Computer Engineering, Memorial University of Newfoundland, St. John's, NL, Canada A1B $3 X 5$ \\ ${ }^{2}$ Department of Mechanical Engineering, Memorial University of Newfoundland, St. John's, NL, Canada A1B 3X5 \\ Correspondence should be addressed to Almahdi Abdo-Allah; atmaa7@mun.ca
}

Received 14 February 2019; Revised 19 April 2019; Accepted 24 April 2019; Published 12 May 2019

Academic Editor: Ciro Aprea

Copyright (c) 2019 Almahdi Abdo-Allah et al. This is an open access article distributed under the Creative Commons Attribution License, which permits unrestricted use, distribution, and reproduction in any medium, provided the original work is properly cited.

In this paper, energy consumption analysis and a process to identify appropriate models based on heat dynamics for large structures are presented. The analysis uses data from heating, ventilation, and air-conditioning (HVAC) system sensors, as well as data from the indoor climate and energy software (IDA Indoor Climate and Energy (IDA-ICE) 4.7 simulation program). Energy consumption data (e.g., power and hot water usage) agrees well with the new models. The model is applicable in a variety of applications, such as forecasting energy consumption and controlling indoor climate. In the study, both data-derived models and a grey-box model are tested, producing a complex building model with high accuracy. Also, a case study of the S. J. Carew building at Memorial University, St. John's, Newfoundland, is presented.

\section{Introduction}

Heating, ventilation, and air-conditioning (HVAC) systems are crucial for indoor climate management and air quality. These systems are also a key factor in overall operational costs. For industrial buildings, nearly one-third of the energy usage depends on HVAC system operation [1-3]. The recent rapid industrialization of the world's developing nations has led to an increase in energy demand, followed by a rapid rise in pollution levels. As a result, researchers are investigating ways to mitigate or prevent further environmental damage through a combination of conservation methods and widescale adoption of renewable energy systems [4].

Ideally, HVAC (heating, ventilation, and air-conditioning) systems are developed to form an interior environment that provides user-comfort with operational cost-efficiency. To maintain consistent user-comfort and affordability amidst changing variables, a suitable control system is needed. Several options have been modeled. One popular method uses data to create a mathematical-based HVAC system that considers input and output variables to find and set system parameters. Data-driven HVAC can readily identify strategies for system refinement and enhancement. These types of model determination are termed system identification (SI) in the literature (ASHRAE, 2005) [5].

In previous studies, researchers categorized modeling approaches into two main types, namely, black box and grey box. For the black box method, no prior information is required, but for the grey-box strategy, there must be a reservoir of preexisting knowledge. Due to these constraints, the black box modeling approach is generally better represented in the literature. Examples of black box models applied to HVAC systems are polynomial forms such as ARX, ARMAX, BJ, and OE. Despite its popularity, the black box model strategy overlooks the physical features of a system, leading to issues around the practical application in real-world designs.

For example, Chi-Man Yiu et al. [6] looked at black box strategies for air-conditioning systems. The researchers contrasted two ARMAX models: the first, a single-input/singleoutput system, and the second, a multi-input/multi-output (MIMO) system. For the MIMO system, Chi-Man Yiu et al. [6] employed parameters derived from the recursive extended least squares method. Mustafaraj et al. [7] investigated temperature and humidity models (ARX, ARMAX, $\mathrm{BJ}$, and $\mathrm{OE}$ ) for office environments, using a black box 
approach. The same researchers [8] continued their work by applying nonlinear autoregressive models with NARX inputs to gauge temperature and humidity levels while comparing and contrasting the outcomes for these models with those of linear ARX models. Additionally, Mustafaraj et al. [8] examined $\mathrm{CO}_{2}$ concentrations' effect on model performance, considering that occupancy levels in a building are directly correlated to $\mathrm{CO}_{2}$. Rabl [9] provided a summary of approaches applied for dynamic analysis of power usage by modeling heat dynamics. These models were applied in studies by Sonderegger [10] and Boyer et al. [11], using differential equations. For dynamic models, parameter estimation and system identification are essentially the same processes.

This paper uses the grey-box method for modeling dynamic systems. This approach, which is accurate and comprehensive, enables the collection of information on a structure's thermal properties [12-14]. Grey-box models employ discrete-time measurement equations and continuous time stochastic differential equations. An HVAC system's yearly power usage can be predicted using energy performance analysis tools, such as SIMBAD, EnergyPlus, eQUEST, HVACSIM+, IDA-ICE, and TRNSYS at set time frames (hourly or less) by a set of equations describing a building's thermal performance. Calculations comparing various design options are usually made for part-load and full-load performance [15-18].

This paper simulates a whole building (the S. J. Carew building in St. John's, Newfoundland) using the IDA Indoor Climate and Energy (IDA-ICE) 4.7 simulation program. In addition to examining the modeled structure's power use, the study investigates a 3D model, a heat model (with variable parameters), and an IDA-ICE model library. The IDA-ICE was developed to investigate different thermal climate zones occurring in indoor environments [19].

By actual details and logged data of a large building in a cold climate, we used the IDA-ICE software and building logged data to model the building in IDA-ICE software. We propose 12 inputs and 12 outputs dynamic model for the system. The dynamic model is required to design and test system controllers before actual implementation. To determine a state-space system model, we use MATLAB system identification toolbox. For the model determination, we used data from IDA-ICE software. Contributions of this paper are building data, proposed system dynamic model, a method to determine the system model, and developed system dynamic model parameters. The primary objectives of this paper are as follows:

(1) Apply the IDA-ICE program to model the S. J. Carew building (Memorial University, St. John's, Newfoundland) using all real dimensions and building materials information from Department of Facilities Management and the Honeywell office, which is responsible for running and monitoring the system.

(2) By using the IDA-ICE software we can divide the single valve of hot water coming from the main room to four distinct units, enabling each air-handling unit (AHU) to have an individual valve for control the mechanical hot water flow for each zone as another

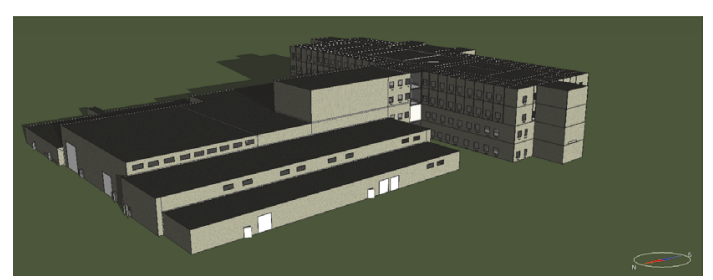

Figure 1: 3D model for the structure.

input of the system are supply fan speed and fresh air dampers position.

(3) Compare the data from the IDA-ICE program with the building logged data for validating the power use outcomes.

(4) Determine the potential of applying the system identification approach to reduce the time needed to simulate the building and use the system model simulation results in identifying the dynamics related to a building's climate control.

\section{The Building for This Case Study}

A case study on the S. J. Carew building, with an interior size of $25,142 \mathrm{~m}^{2}$, is conducted. The building is located on the campus of Memorial University, St. John's, Newfoundland, and includes several teaching rooms and research labs for the Memorial's Faculty of Engineering and Applied Science. The building also features a large cafeteria. There are four individual air-handling units (AHUs) in 300 zones within the building. Figure 1 illustrates a 3D model for the structure, applying the IDA-ICE program mentioned in the previous section, while Table 1 provides an energy report.

\section{Simulation Tool}

The S. J. Carew building is modeled by employing IDA-ICE as a dynamic thermal simulation tool. This program is selected because it is widely accepted as a viable thermal building performance simulator towards the study of power usage and indoor thermal climate of whole buildings [19]. The IDAICE program uses symbolic equations framed in a modeling language and a variable time-step differential-algebraic (DAE solver). The models can be expressed through the Neutral Model Format (NMF)/Modelica and act as both computer code and readable document, which are applicable to various simulation environments [20,21].

The simulation tool IDA-ICE 4.7 is employed to predict the power usage and interior climate of the S. J. Carew building. The IDA-ICE 4.7 tool is ideal for modeling of multiple-zone HVAC systems as in the S. J. Carew building. IDA-ICE 4.7 is able to determine the general thermal comfort level of the building by measuring the internal air quality (IAQ) and performing dynamic simulations. The heat exchanger uses controllers to maintain zonal temperatures, which can be set as fixed points by modulating control valves. Meanwhile, in the real system (as shown in Figure 2), a hot 


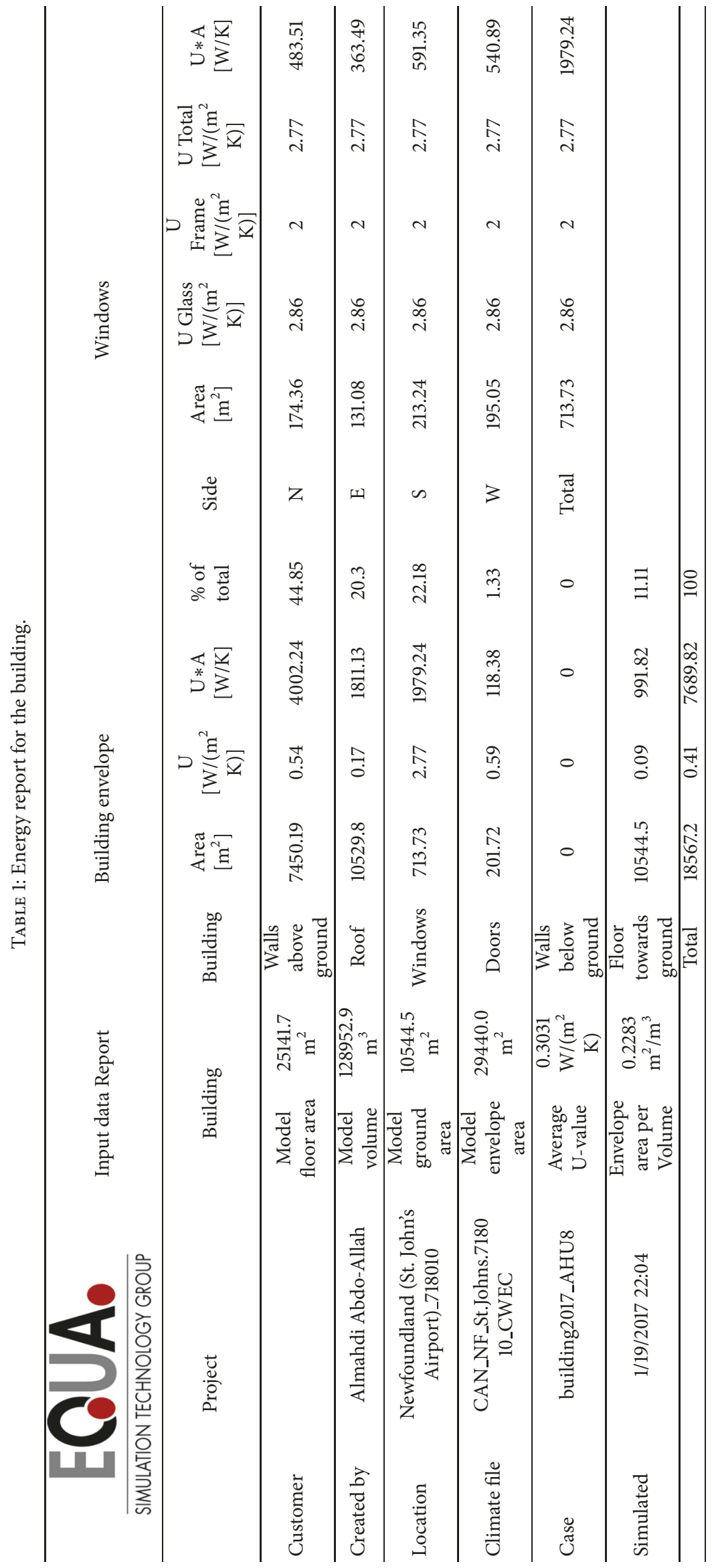




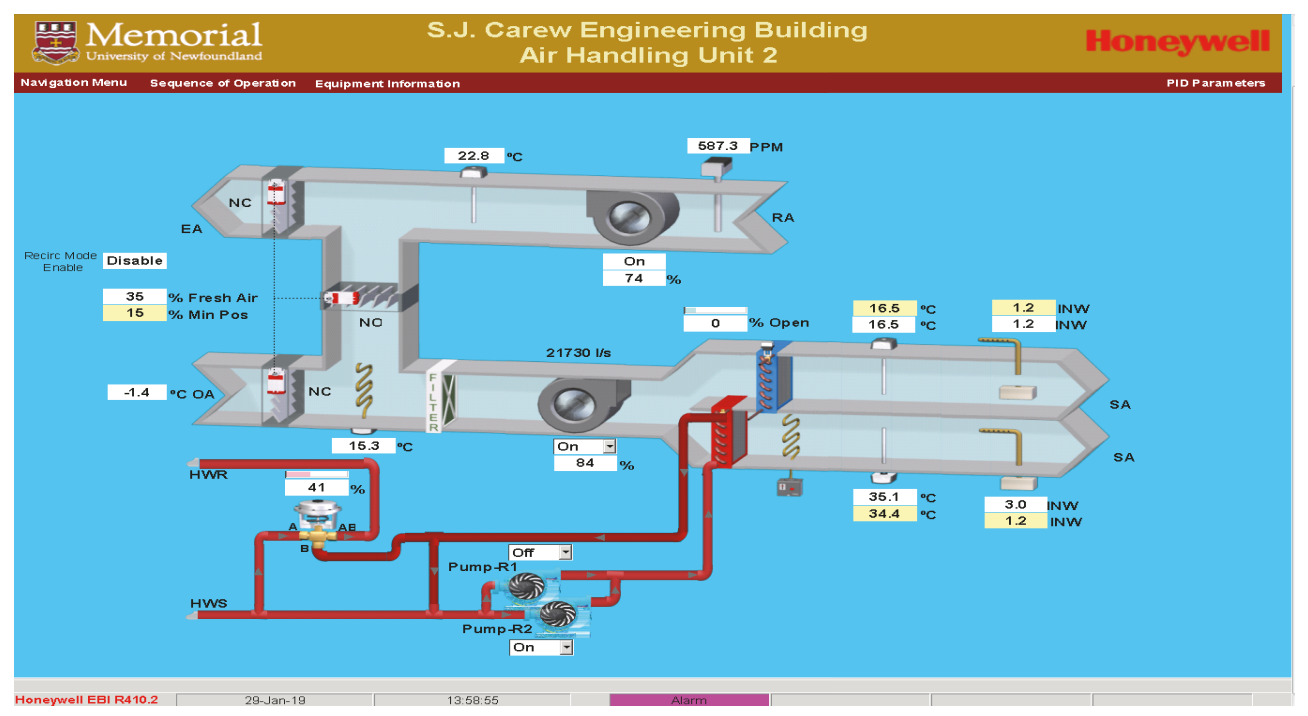

Figure 2: $\mathrm{AHU}_{2}$ for S. J. Carew building.

water valve collects relevant data for water heated by a heating coil. Although the building's system features a single valve for its hot water production, the IDA-ICE software divides the single valve into four distinct units, enabling each airhandling unit (AHU) to have an individual valve $[22,23]$.

\section{Building Model}

IFC files were used to develop a simulation model from the building information model (BIM). As shown in Figure 3, the third floor of the building features an AHU and all floors in the building have their own individual AHU.

Data from the Facilities Management Department at Memorial University are used to source construction information regarding building dimensions and elements such as windows, doors, and walls. The data then are inputted to the IDA-ICE program.

Figure 4 depicts eight different kinds of windows used in the Carew building, while Figure 5 illustrates the building's south elevation. Heating system information (e.g., radiator type and position) is presented in Figure 6, and Figure 7 depicts the main room's ventilation system for $\mathrm{AHU}_{1}, \mathrm{AHU}_{2}$, and $\mathrm{AHU}_{3}$. Each of the areas has individual internals loads (i.e., occupancy and light based on floor type and usage) that have been determined by applying national building code monthly values. The ventilation design determines the supply and exhaust air flows, with standard commercial building pressure coefficients applied. There are doors dividing nearly all of the areas in the structure, enabling bidirectional air flow (even through closed doors). Air tightness is measured as an n50-parameter, while infiltration and exfiltration are simulated using the IDA-ICE air flow network feature.

\section{Simulation Results}

The IDA-ICE 4.7 program was used to analyze energy use in the S. J. Carew building at Memorial University, St.
John's, Newfoundland. The analysis involved a number of factors, such as weather data, infiltration, external/internal heat gain, and overall heat capacity. The simulation was done for the course of one full year (January 1, 2016, to December 31, 2016). The space heating and total energy consumption analysis results for the building in five points as following.

\subsection{AHU Results}

(i) AHUs Temperature. Figure 8 shows $\mathrm{AHU}_{1}$ supply air and return air, as well as the outdoor air temperature. As can be seen, the air temperature represents a mixture of temperatures from individual zones, while the air supply temperature represents the temperature of the air terminal zone following any alterations made to the duct or fan systems. The supply air temperature set-point refers to the air temperature prior to these alterations.

(ii) AHU Airflow. The flows represent the total flow from every zone impacted by $\mathrm{AHU}_{1}$ (Figure 9) and have been multiplied according to weight (i.e., how many zones are the same type). This value is included in every zone. The flow is volumetric and assessed for actual temperatures. Therefore, it can differ from the set-point flow for each zone. Set-point flows are determined from mass flows based on variations in density.

(iii) Heating and Cooling AHUs Coils. Figure 10 depicts the central cooling and energy for $\mathrm{AHU}_{1}$. In circuits that are water-based, the energy consumption can be measured in the circuit according to temperature changes and mass flow (i.e., supply/return). Therefore, heat can be calculated after generation losses are included, but prior to the calculation of emission and distribution losses. Cooling energy is included as a positive quantity in the calculations. 


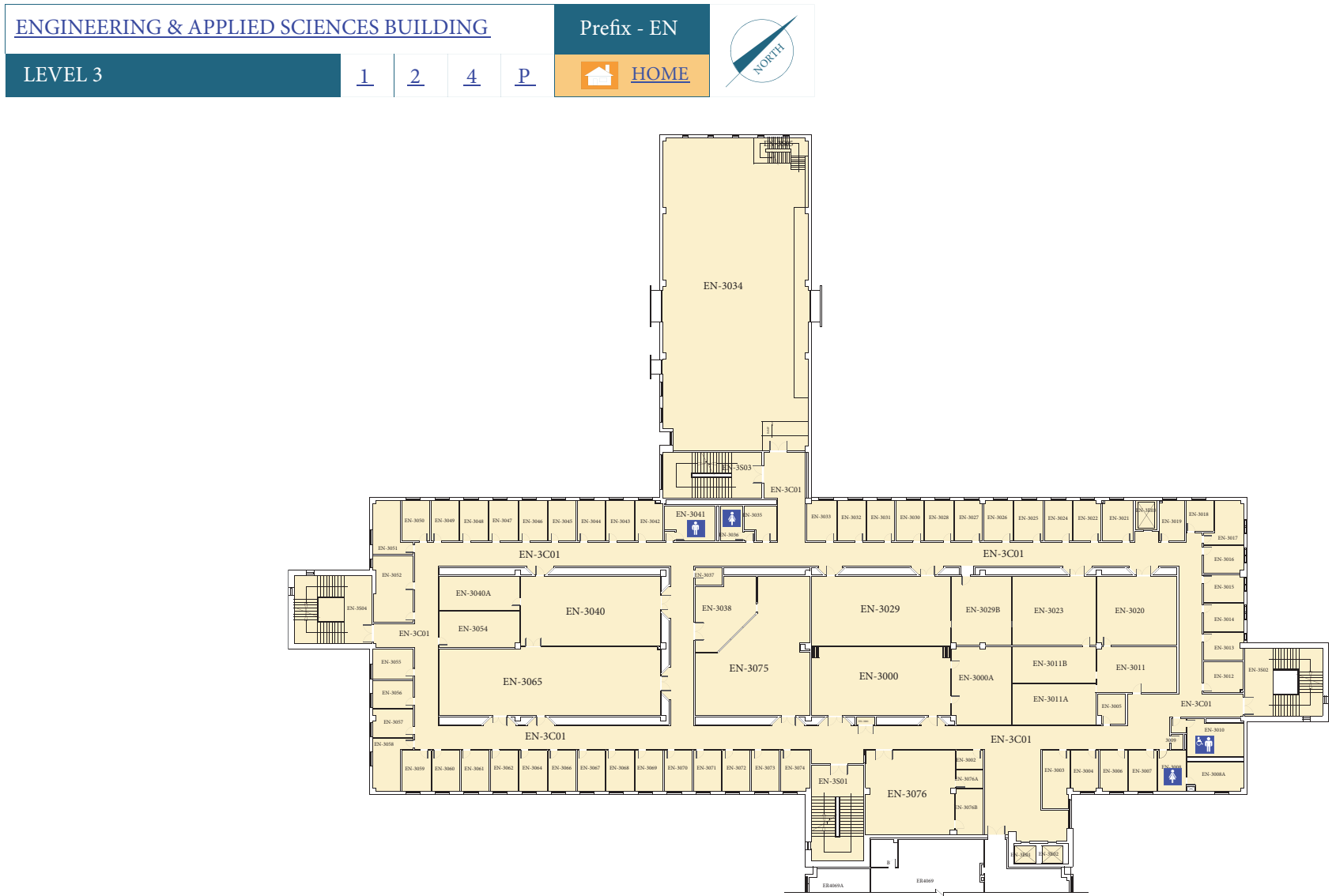

FIGURE 3: The third floor of the building.

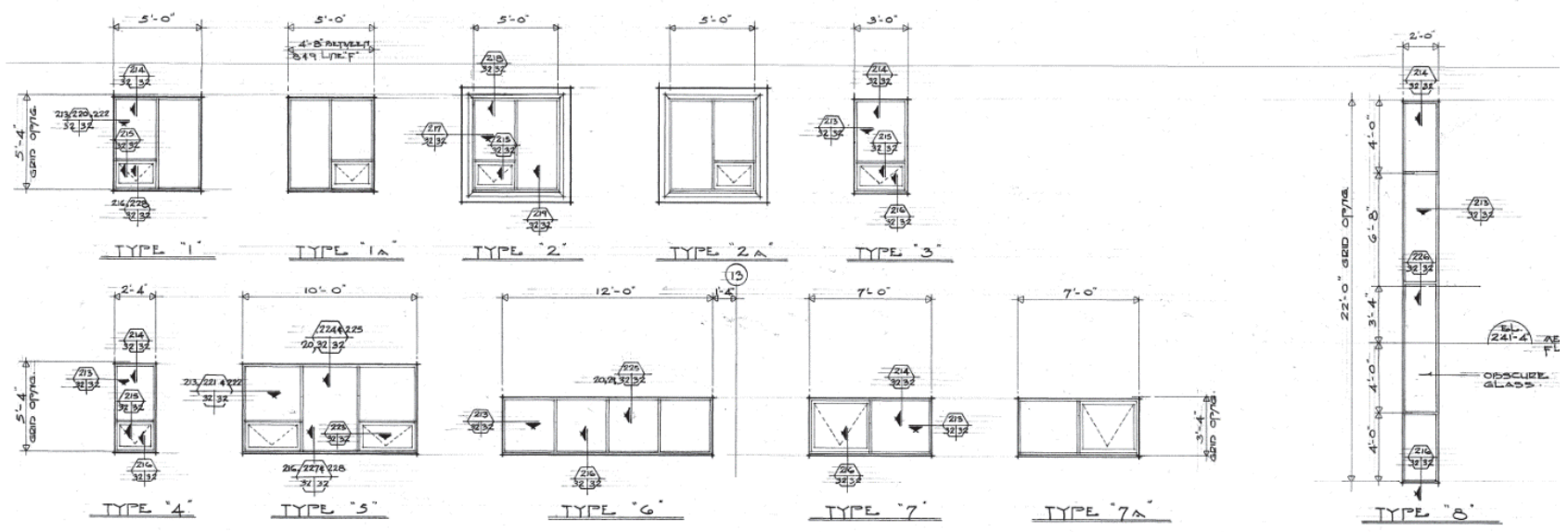

FIgURE 4: Details of windows used in the Carew building.

5.2. Heat Balance. Figure 11 depicts the zones' sensible (dry) and full latent (moist) heat balance. To find the sensible heat balance only, the details for the zone's power report need to be logged. In this setup, the control volume indicates air-wetted surface area located at the room unit zone-side, backed by an air gap. Heat balance contributions can be allocated as shown in Figure 11. (i) Equipment Heat. This type of heat emanates out of equipment like printers and computers as a form of radiant or convective heat.

(ii) Floor and Wall Heat. As the control volume is positioned directly below the surface of floors and walls, any measurement of heat indicates the presence of conductive heat passing 


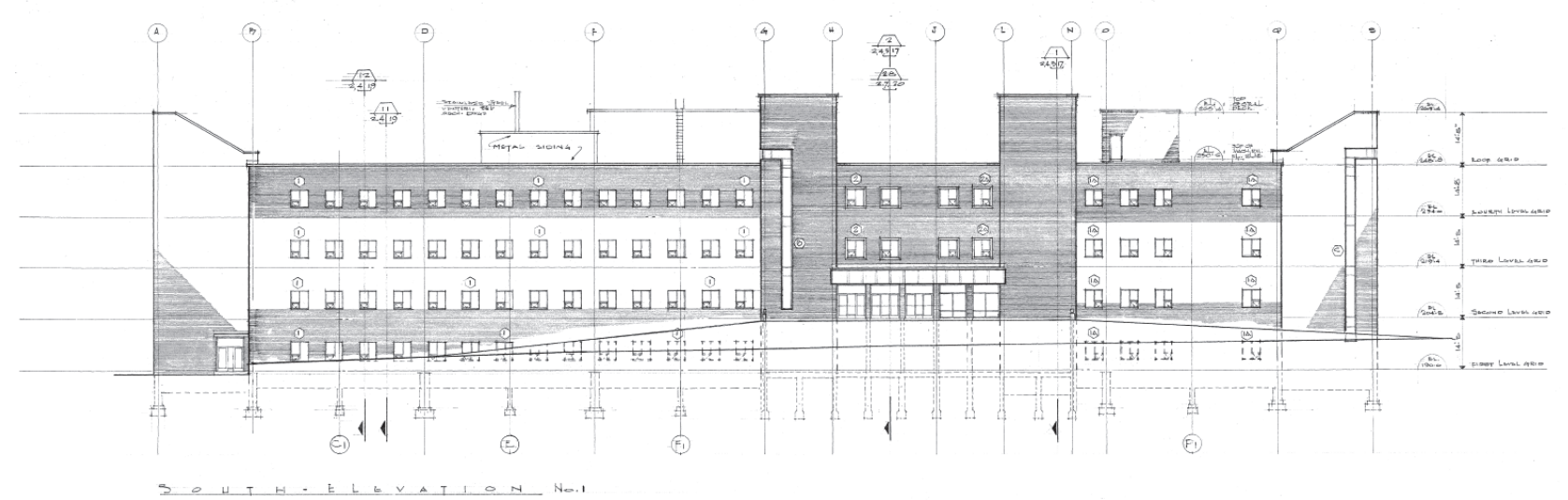

FIGURE 5: South elevation of the building.

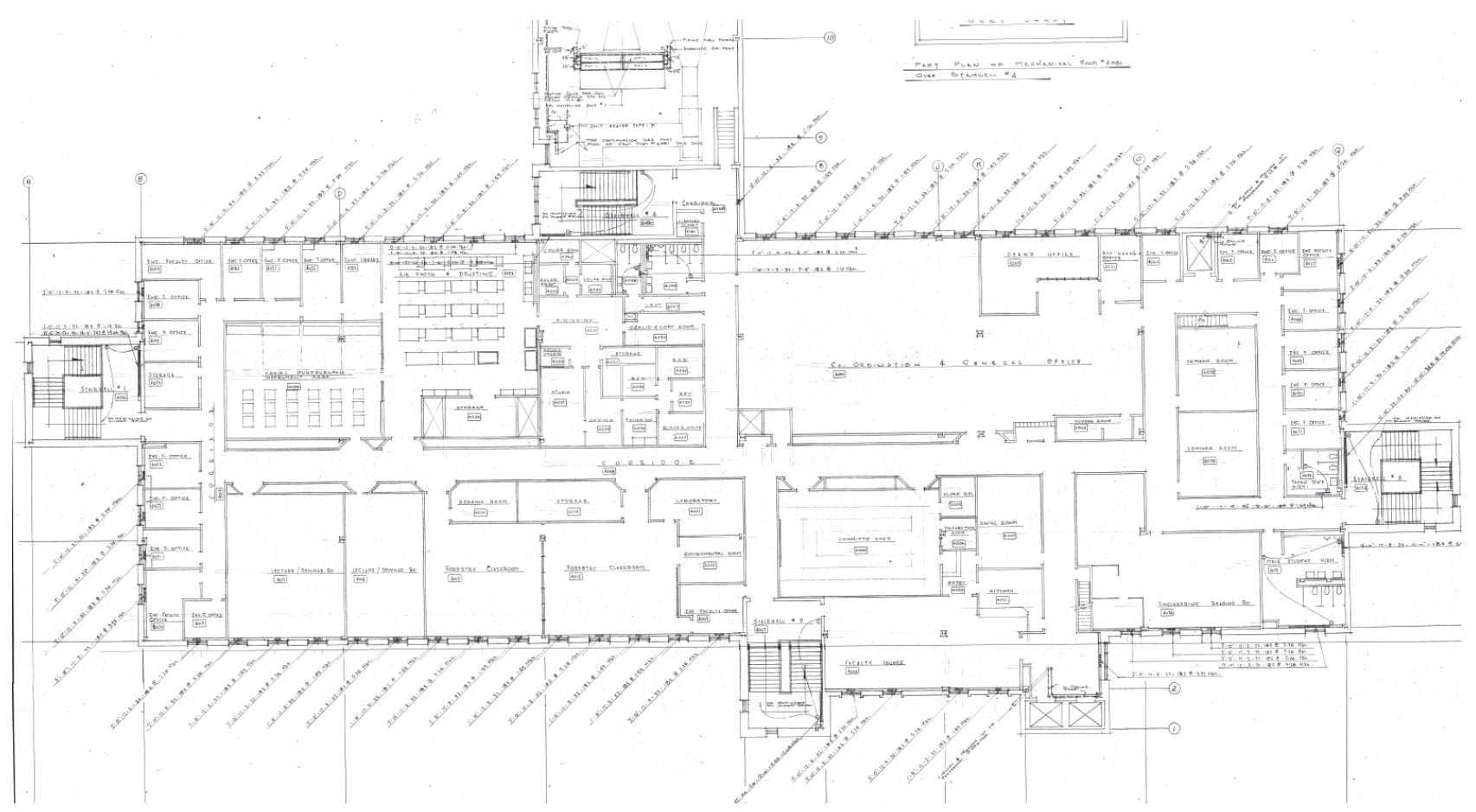

Figure 6: Fourth-floor layout.

through the structural element. This type of thermal energy can include net transmission and heat storage, in addition to internal heat functions (e.g., in-floor radiant heat). The thermal energy that has been stored as a function of room masses, such as in furniture, also is in this category.

(iii) Daylight Heat. This type of heat describes sunlight streaming into open doors or through windows, taking into consideration any short-wave radiation which exists. Solar radiation that has been absorbed and retransmitted is excluded from this category.

(iv) Heating/Cooling Room Heat. This type of heat is represented by controlled room units (e.g., radiators or chilled beams). In hydronic systems, there is an automatic calculation to account for the radiation and convection aspects, as described in the manual. Floor heating is excluded from this category.

(v) Window Heat. This type of heat describes heat emitted from window surfaces, such as through retransmitted absorbed solar radiation or through conduction. Long-wave radiation entering via openings such as opened doors falls under this category of heat. Solar radiation can have two major impacts on a room's heat:

(i) It can be absorbed by the window covering or pane and then emanate through the room as a radiative or convective process. 


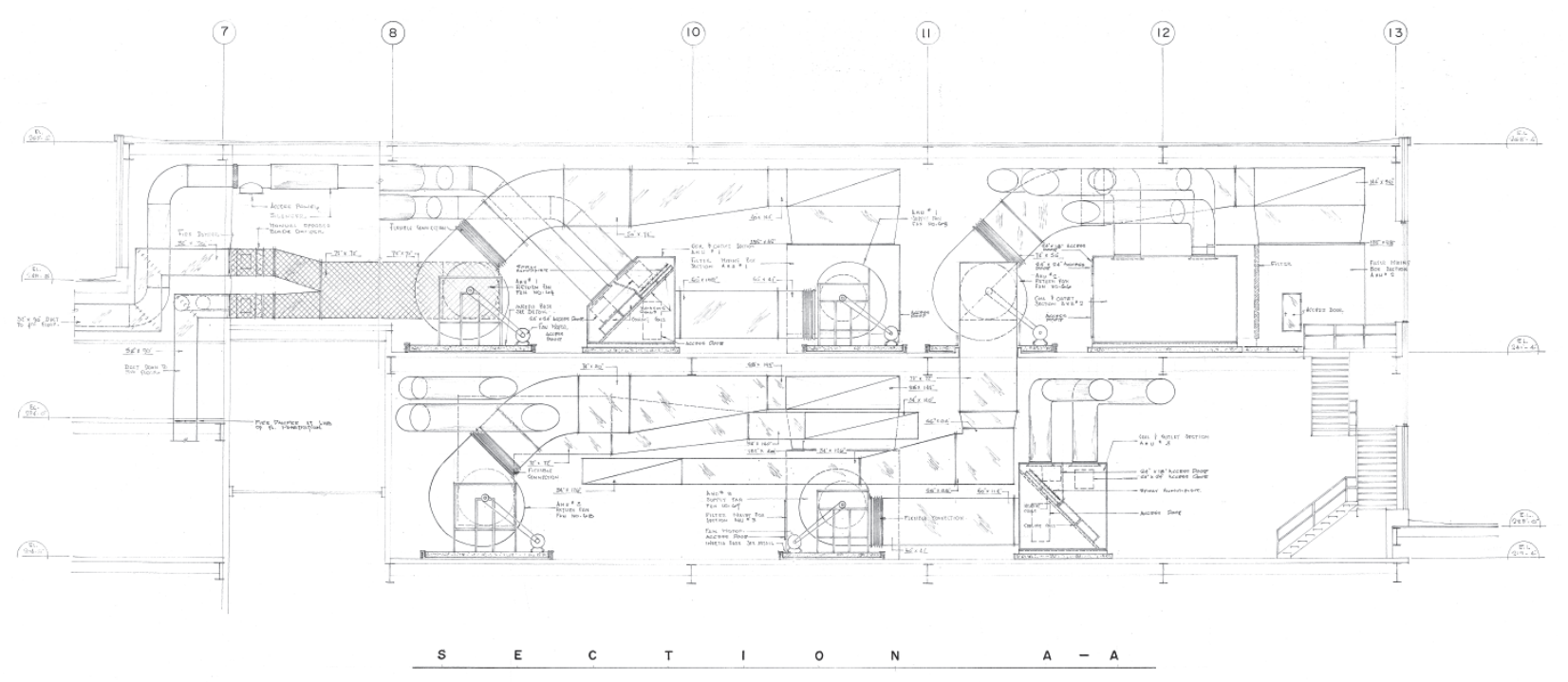

FIGURE 7: Main room's ventilation system.

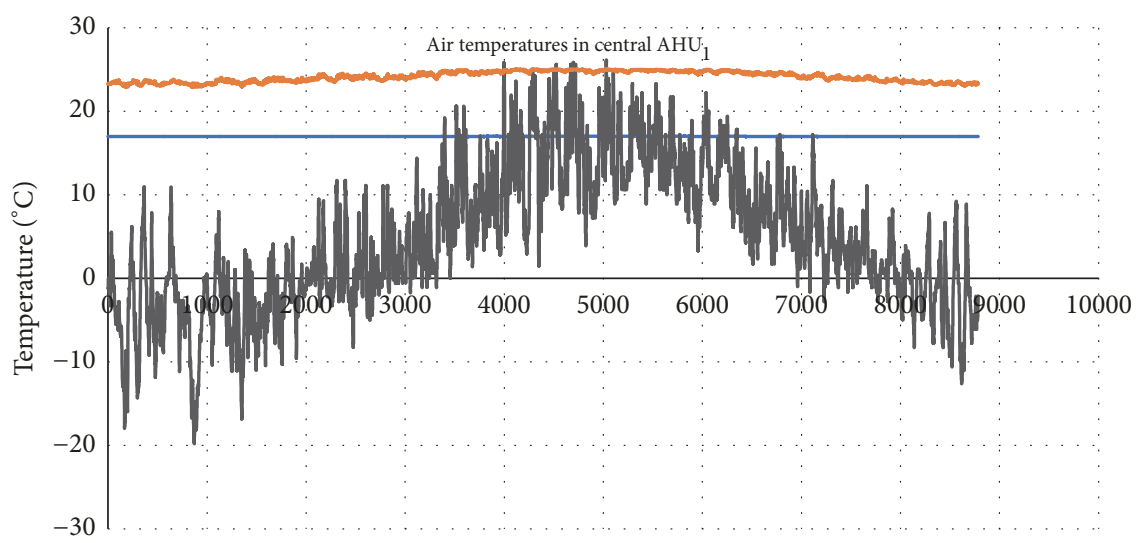

Time (h)

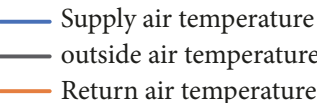

FIGURE 8: $\mathrm{AHU}_{1}$ supply air, return air, and outdoor air temperature.

(ii) It can be directly transmitted as short-wave radiation and be reflected by room surfaces until finally absorbed by internal room masses (furniture, equipment, people, etc.).

(vi) Air Flow Heat. This describes all air flows, including infiltration, flowing from other zones and mechanical ventilation.

5.3. Energy Delivered. The report on the energy delivered provides a general overview of the total energy purchased or generated in the S. J. Carew building, as shown in Figure 12. The reported items are matched to the energy meters. The report also shows the primary form of energy employed, as well as the cost and estimates for $\mathrm{CO}_{2}$ emitted. These are presented according to the structure's floor area and with regard to absolute values. Conversion factors from the meter energy to other measures are given as energy meters.

5.4. Results: Energy from Systems. The results also provide a general review for HVAC system energy flow. As shown in Table 2, the review is in three categories: use energy, utilized free energy, and auxiliary energy. The results provide a means to validate real data and then apply this data for system identification to obtain the Carew building's HVAC system's state-space model.

5.5. Results: Energy from Zones. The results provide information on the sensible heat balance in the Carew building's 


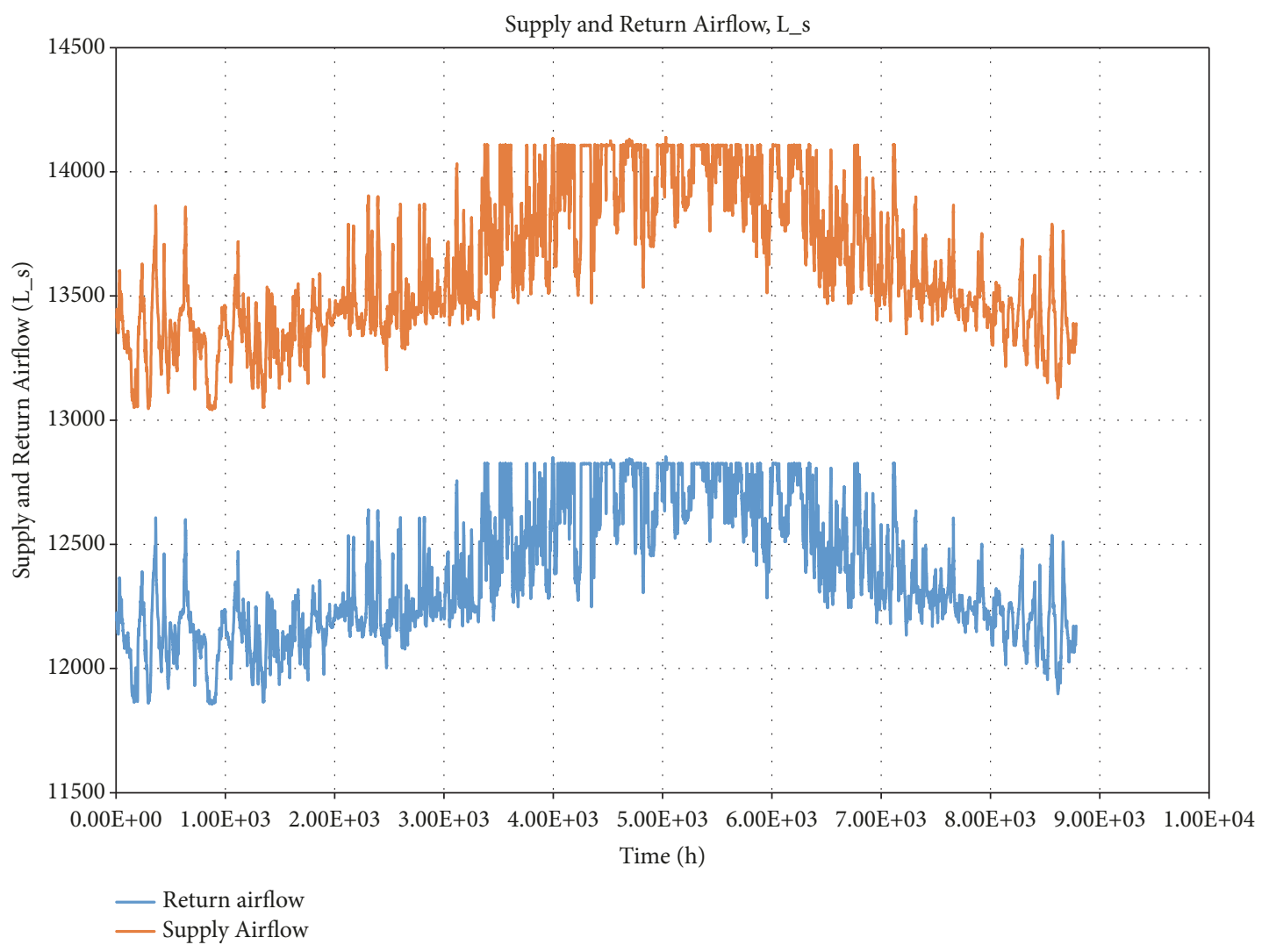

FIGURE 9: $\mathrm{AHU}_{1}$ supply and return air flow.

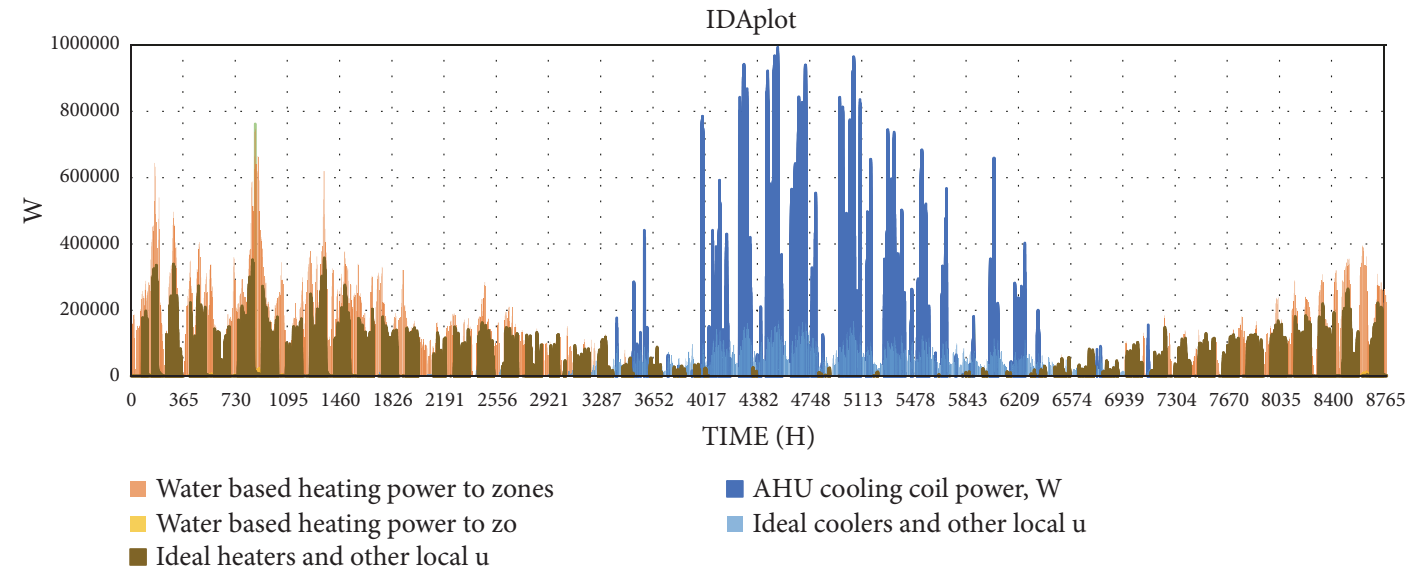

FIgURE 10: Central heating and cooling power of $\mathrm{AHU}_{1}$.

zones. Information on total (i.e., dry and wet) heat balance, are presented in the heat balance Figure 6. The data are provided for monthly and one-year (simulation period) basis. Figure 13 provides details on envelope transmission losses, with control volume being positioned at the surface of the floor as well as on the ceiling and inside walls. For slab (embedded) cooling and heating processes, the control volume also involves activated layers and thus includes large thermal masses.

\section{Simulation Validation for IDA-ICE}

A viable model must provide accurate results and also meet the required specifications. In the present work, the building data used was provided by Memorial University's Department of Facilities Management and the Honeywell Office. The data provided in Tables 3 and 4 (energy and hot water consumption) for the S. J. Carew building were collected between April 2012 and May 2017, inclusive. These 


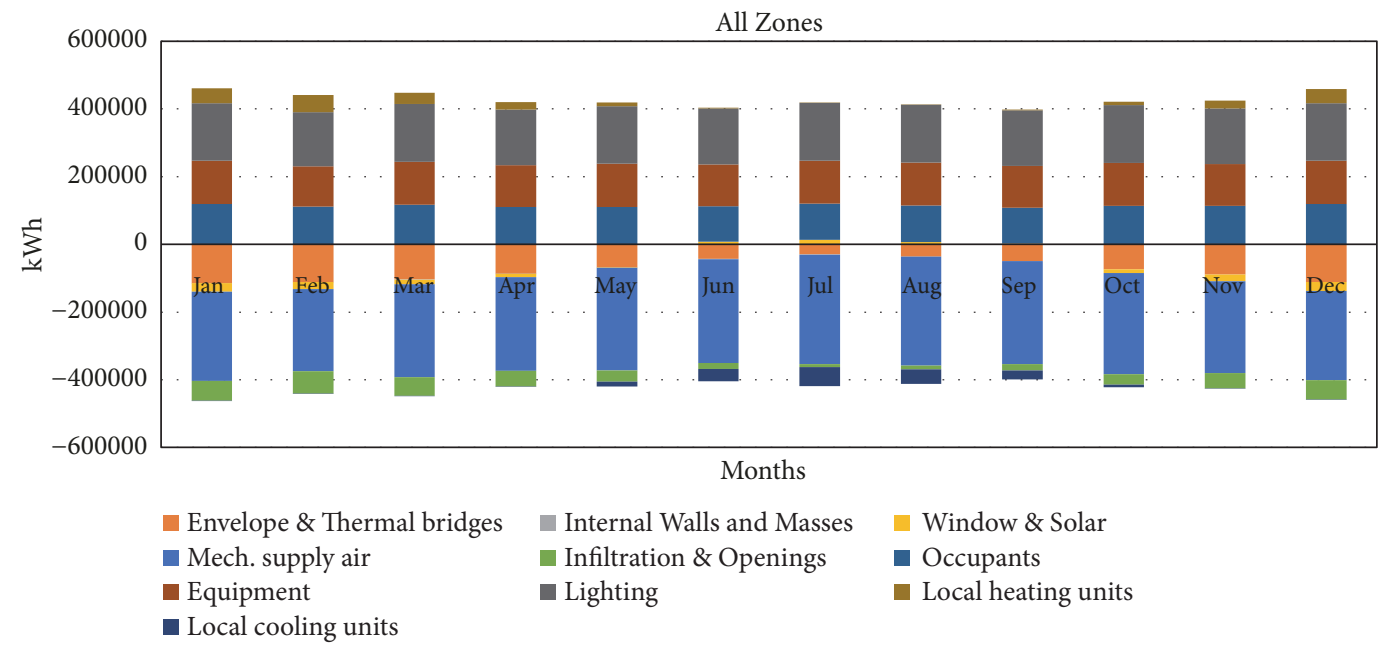

FIGURE 11: Results for building heat balance.

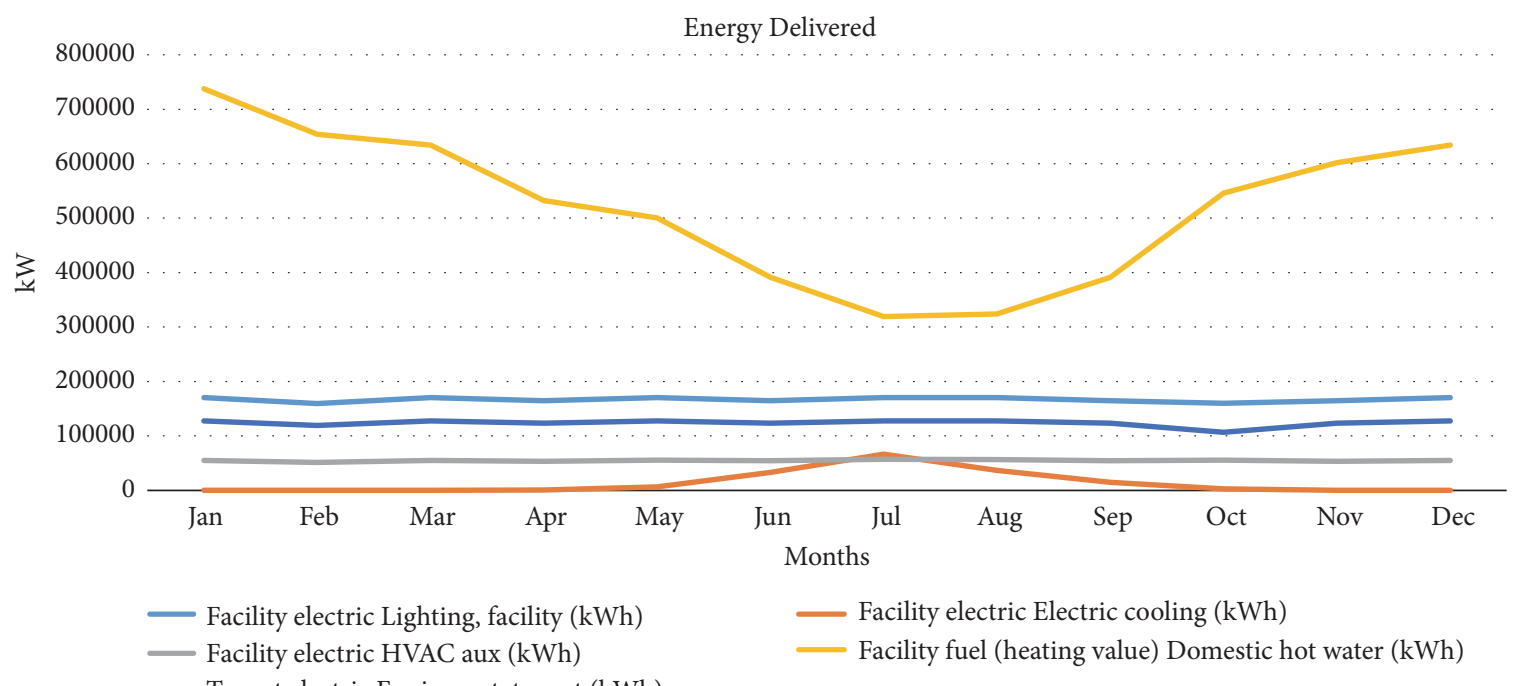

— Tenant electric Equipment, tenant $(\mathrm{kWh})$

FIGURE 12: Energy delivered.

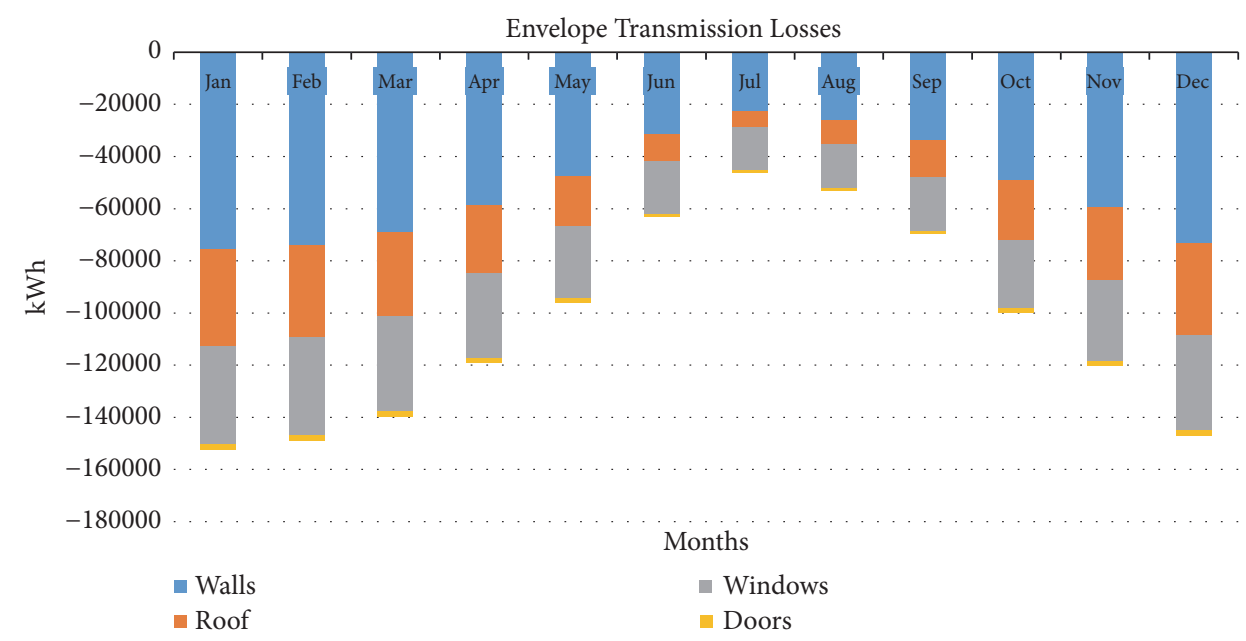

FIGURE 13: Details on envelope transmission losses. 


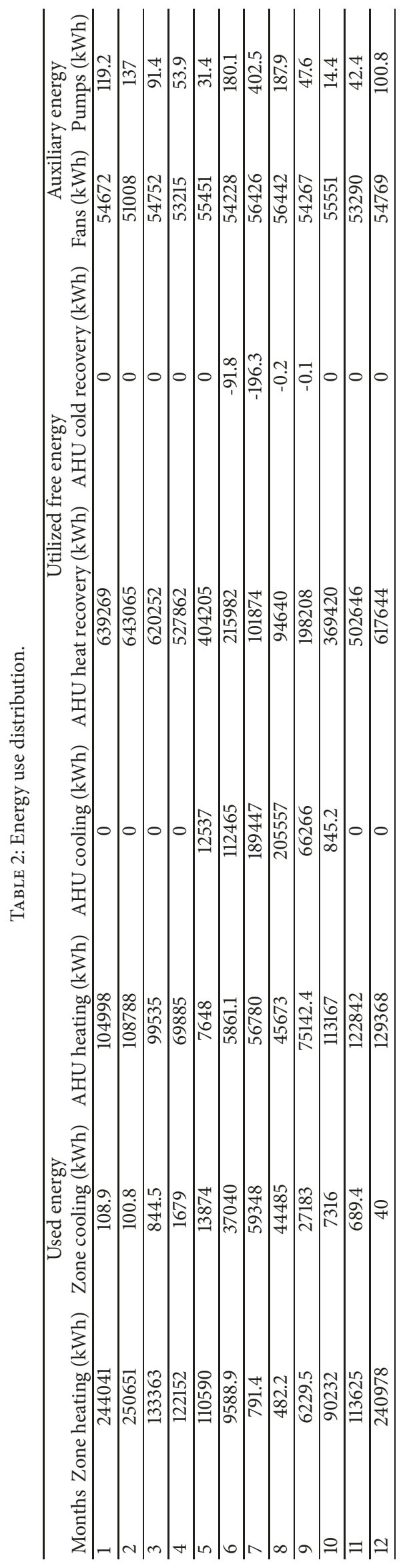


TABLE 3: Energy from hot water consumption.

\begin{tabular}{|c|c|c|c|c|c|c|}
\hline & Y2012 & Y2013 & Y2014 & Y2015 & Y2016 & Y2017 \\
\hline MONTH & MMBTU & MMBTU & MMBTU & MMBTU & MMBTU & MMBTU \\
\hline $\mathrm{APR}$ & 1,646 & 1,838 & 1,932 & 2,333 & 2,109 & 1,640 \\
\hline MAY & 1,318 & 1,446 & 1,806 & 1,956 & 1,745 & 1,985 \\
\hline JUN & 1,164 & 1,251 & 1,273 & 1,615 & 1,391 & 0 \\
\hline JUL & 774 & 1,067 & 856 & 1,464 & 1,150 & 0 \\
\hline AUG & 525 & 932 & 974 & 1,019 & 1,071 & 0 \\
\hline SEP & 391 & 958 & 1,017 & 1,289 & 1,368 & 0 \\
\hline OCT & 1,438 & 1,519 & 1,510 & 1,793 & 1,906 & 0 \\
\hline NOV & 1,659 & 1,740 & 1,803 & 2,117 & 1,946 & 0 \\
\hline DEC & 1,915 & 2,313 & 2,143 & 2,073 & 2,732 & 0 \\
\hline JAN & 2,389 & 2,228 & 2,638 & 2,546 & 2,898 & 0 \\
\hline FEB & 2,051 & 2,175 & 2,512 & 2,276 & 2,473 & 0 \\
\hline MAR & 1,939 & 2,405 & 2,615 & 2,502 & 2,605 & 0 \\
\hline TOT & 17,210 & 19,871 & 21,079 & 22,983 & 23,394 & 3,625 \\
\hline LITRES & 565,029 & 633,115 & 666,618 & 719,885 & 762,559 & 116,177 \\
\hline
\end{tabular}

TABLE 4: Electrical power consumption.

\begin{tabular}{|c|c|c|c|c|c|c|}
\hline & Y2012 & Y2013 & Y2014 & Y2015 & Y2016 & Y2017 \\
\hline MONTH & $\mathrm{kWh}$ & $\mathrm{kWh}$ & kWh & kWh & $\mathrm{kWh}$ & kWh \\
\hline APR & 366,300 & 375,458 & 462,454 & 526,557 & 485,348 & 444,139 \\
\hline MAY & 393,773 & 425,824 & 471,612 & 503,663 & 398,352 & 434,982 \\
\hline JUN & 434,982 & 357,143 & 407,509 & 503,663 & 489,927 & 0 \\
\hline JUL & 407,509 & 508,242 & 563,187 & 425,824 & 467,033 & 0 \\
\hline AUG & 366,300 & 366,300 & 471,612 & 462,454 & 494,505 & 0 \\
\hline SEP & 402,930 & 393,773 & 425,824 & 430,403 & 370,879 & 0 \\
\hline OCT & 439,560 & 407,509 & 425,824 & 526,557 & 434,982 & 0 \\
\hline NOV & 412,088 & 476,190 & 512,821 & 439,560 & 489,927 & 0 \\
\hline DEC & 393,773 & 444,139 & 526,557 & 434,982 & 508,242 & 0 \\
\hline JAN & 439,560 & 462,454 & 476,190 & 448,718 & 476,190 & 0 \\
\hline FEB & 398,352 & 439,560 & 494,505 & 444,139 & 430,403 & 0 \\
\hline MAR & 402,930 & 416,667 & 467,033 & 508,242 & 476,190 & 0 \\
\hline TOT & $4,858,059$ & $5,073,260$ & $5,705,128$ & $5,654,762$ & $5,521,978$ & 879,121 \\
\hline
\end{tabular}

were used to compare, and contrast power consumption derived from real data with power consumption derived from the IDA-ICE program data.

The first step for comparison was to verify design details for the Carew building. These details included aspects such as building materials, location, dimensions, total area, etc. The second step was to make a comparison using the file for outdoor air temperature/weather as represented in the IDA-ICE program (based on readings from St. John's Airport, [ASHRAE, 2013]) and the building's actual outdoor air temperature obtained from the Honeywell software data. Figure 3 depicts the sensor $\left(-1.4^{\circ} \mathrm{OA}\right)$; the average of the temperature readings from 2016 in one-hour time samples for both data was the same.

A viable model needs to have both accurate results and the ability to satisfy any required specifications. Figure 14 shows the IDA-ICE model of hot water usage from January to December 2016. The energy consumption for hot water was more than $800,000 \mathrm{kWh}$ in Jan and Dec. Also, it was almost 300,000 in the summer time (Jul and Aug). Furthermore, although the actual data for hot water usage measured slightly low in some months and slightly high in others, it compared well to the IDA simulated data. Regarding overall energy consumption, the modeled data are only somewhat different than the actual data. Figure 15 shows the actual (measured) data as moderately higher than the simulation data, but these slight differences could be due to discrepancies in the lab readings due to miscalibrated equipment.

\section{System Identification}

Our study used the IDA-ICE 4.7 simulation software for measuring the interior environment as well as the overall energy performance. This software is able to simulate and model multiple-zoned HVAC systems and is also gauge 


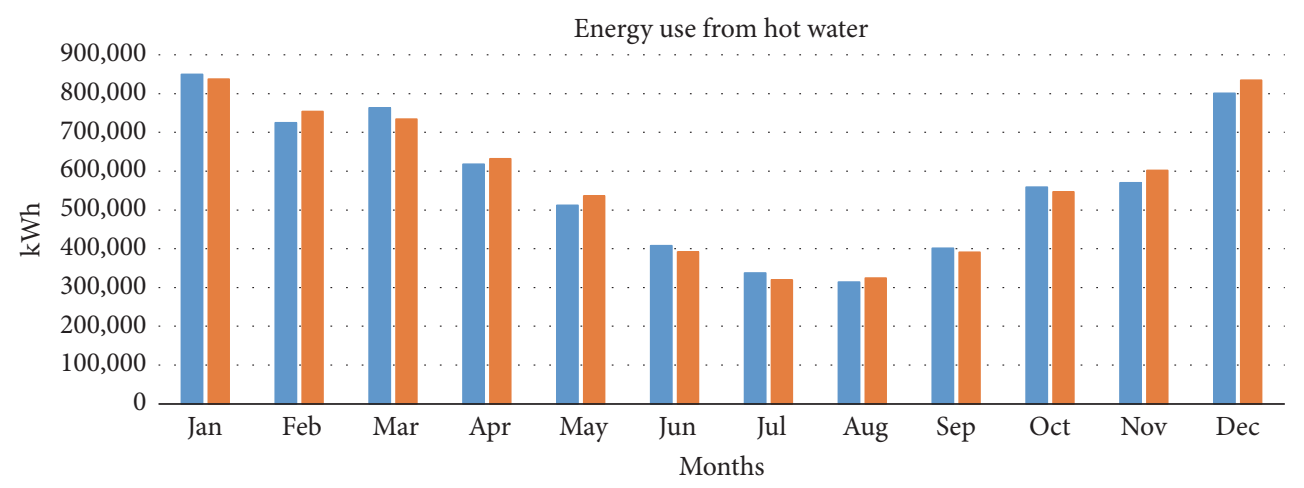

Real data

IDA-ICE program data

FIGURE 14: Energy use from hot water.

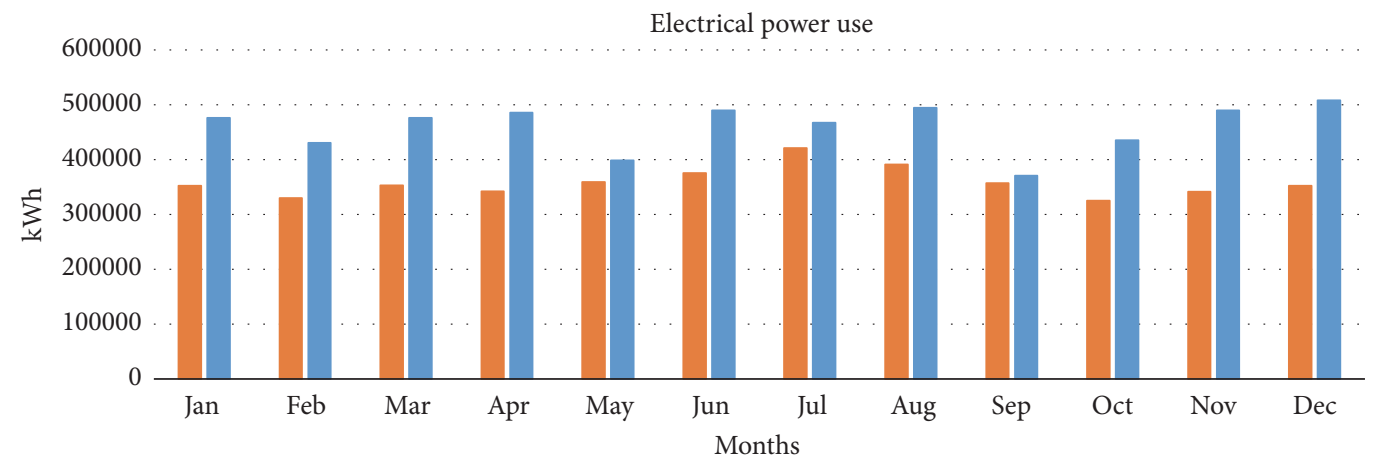

IDA-ICE program data

Real data

FIgURE 15: Electrical power use.

interior air quality (IAQ), energy requirements, and thermal comfort levels. To model the S. J. Carew building, the zonal inputs and outputs must be included in the identification data. There are three main steps in system identification [2427]:

(i) Collecting the data towards model identification.

(ii) Choosing an appropriate model structure.

(iii) Building a model that provides the best functionality (i.e., satisfies specifications and gives accurate results).

During these steps, the focus is on optimizing the chosen model to suit a real-life system. In this study, a structure is used that features four AHUs as a means for identifying the state-space model of the system. The data used for system identification were collected during the winter months, which means that the cold-water valve was not operating. Additionally, because the S. J. Carew building has four floors, the system features twelve inputs and twelve outputs overall, calculated from three inputs $(U)$ and three outputs $(Y)$ per floor. Figure 16 illustrates the details.

(1) Zonal Temperature ${ }^{\circ} \mathrm{C}\left(\mathrm{T}_{\mathrm{z}}\right)\left(y_{1}, y_{4}, y_{7}, y_{10}\right)$. These data are derived from the IDA-ICE software. Although the actual system features sensors in every room, the temperature on each floor still needs to be measured. The data from the IDA-ICE software are used to control the hot water valve. Figure 17 illustrates the outputs.

(2) Hot Water Valve for Heating Coil/Zones $\left(u_{1}, u_{4}\right.$, $\left.u_{7}, u_{10}\right)$. These data are also derived from the IDA-ICE software. In the actual system (as shown in Figure 16), a hot water valve collects data on hot water use. Note that this system only has one valve for hot water production, whereas in the IDA-ICE software there are four valves, which enables every floor to have a separate valve. Figure 18 shows these inputs as percentage of opening and closing operation of the hot water valves.

(3) Fresh Air Dampers $\left(u_{3}, u_{6}, u_{9}, u_{12}\right)$. As shown in Figure 18, the fresh air sensors positioned in AHUs are able to gauge, in percentage, the amount of fresh air entering the building. The sample time $\left(T_{s}\right)$ used in these calculations is used in all data.

(4) $\mathrm{CO}_{2}$ Levels $\left(\mathrm{CO}_{2}\right)\left(y_{3}, y_{6}, y_{9}, y_{12}\right)$. This data is obtained from the sensors for return air flow ducts for individual AHUs. Figure 19 depicts $\mathrm{CO}_{2}$ levels occurring in AHUs. These outputs can be applied in moderating fresh air dampers. 


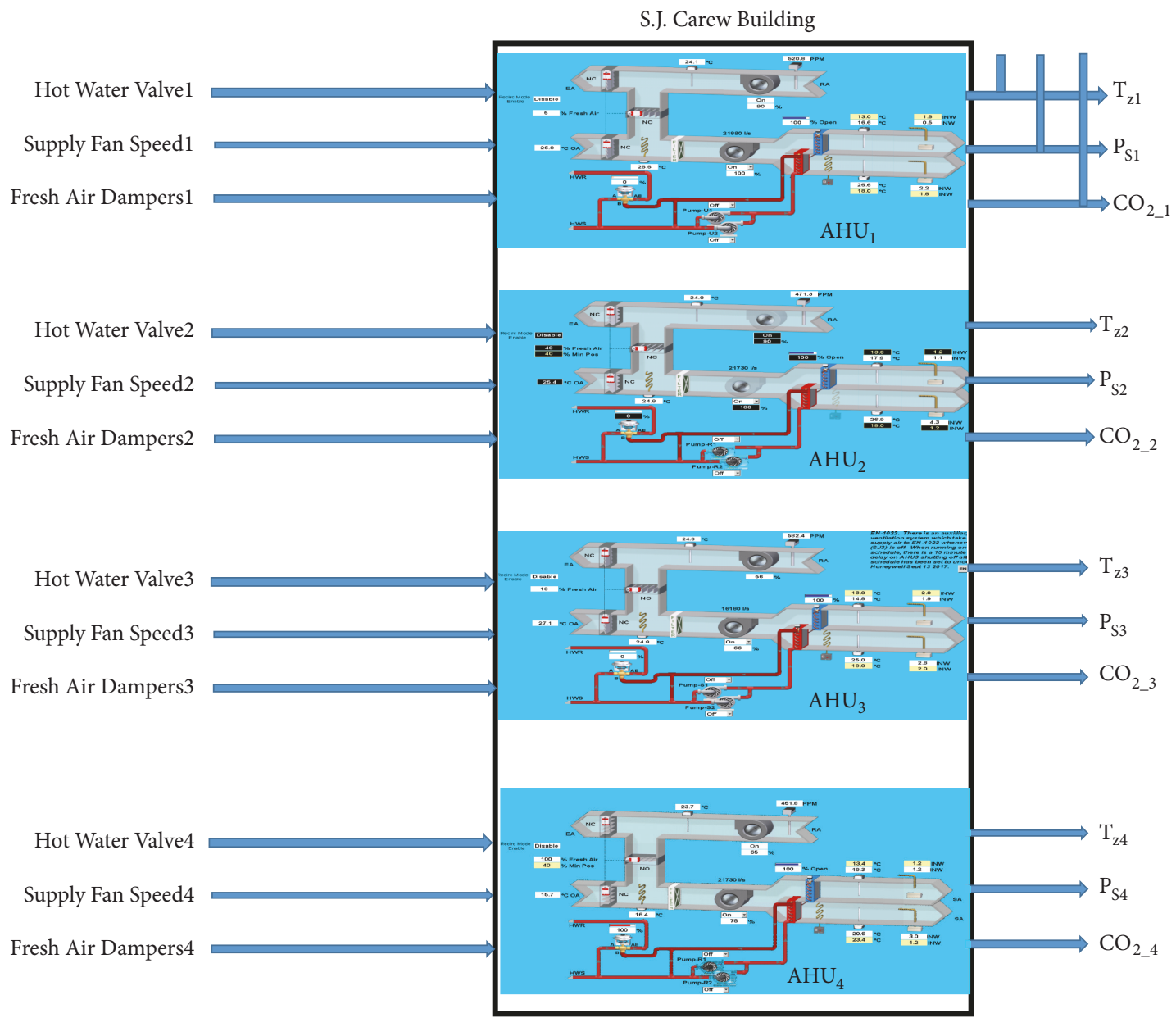

FIGURE 16: Inputs and outputs of the system.

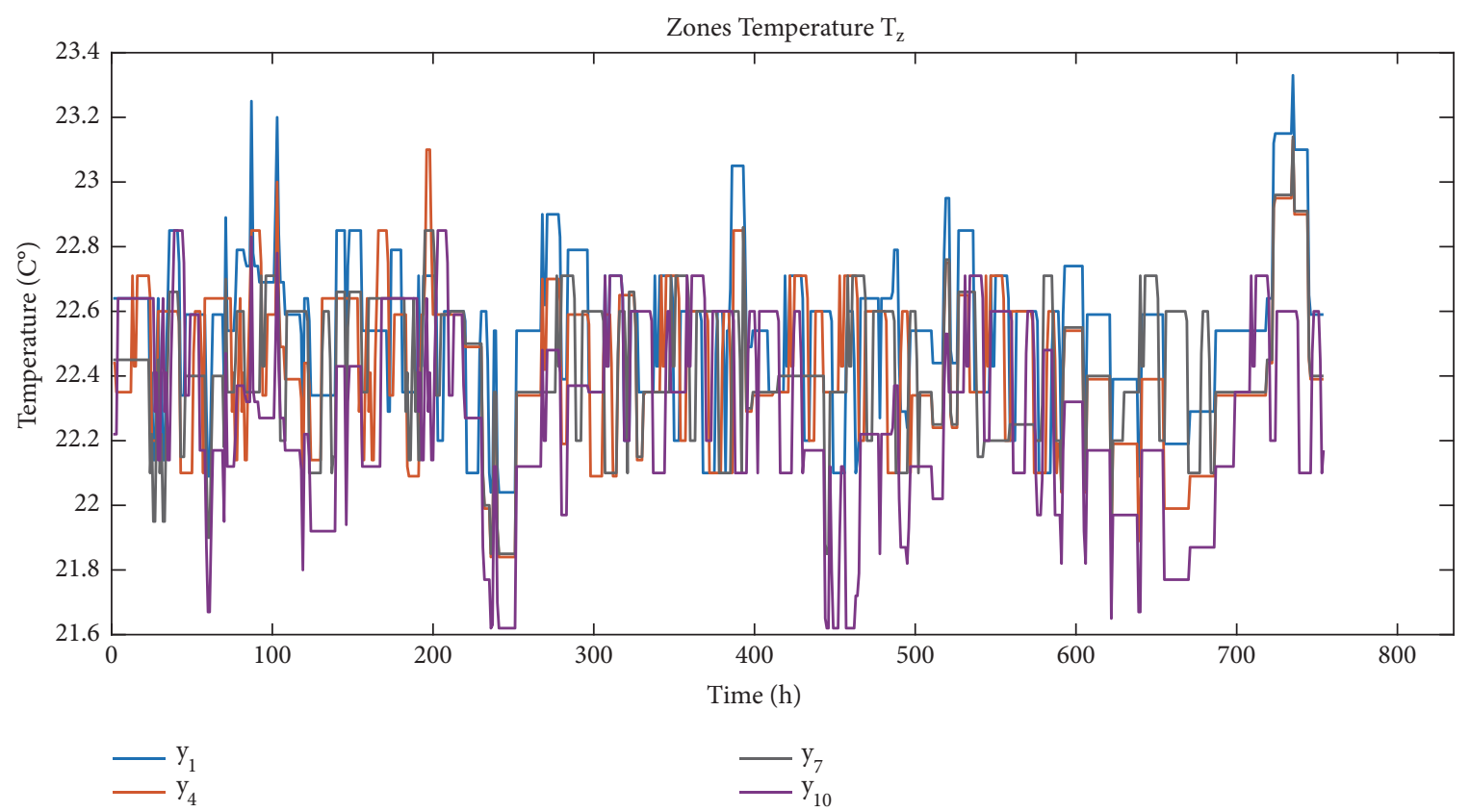

FIgURE 17: Zones temperature. 

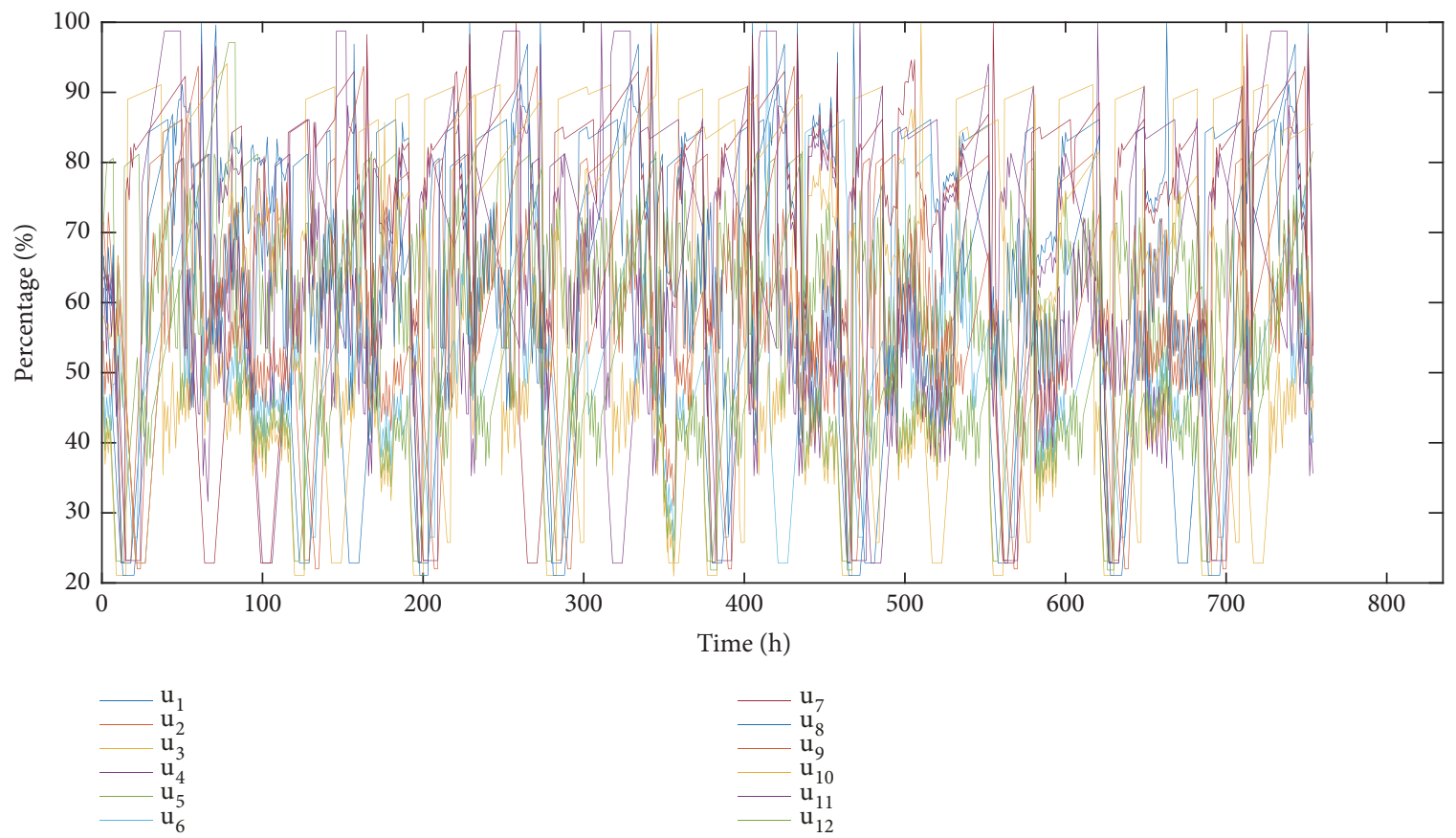

Figure 18: All inputs of the system.

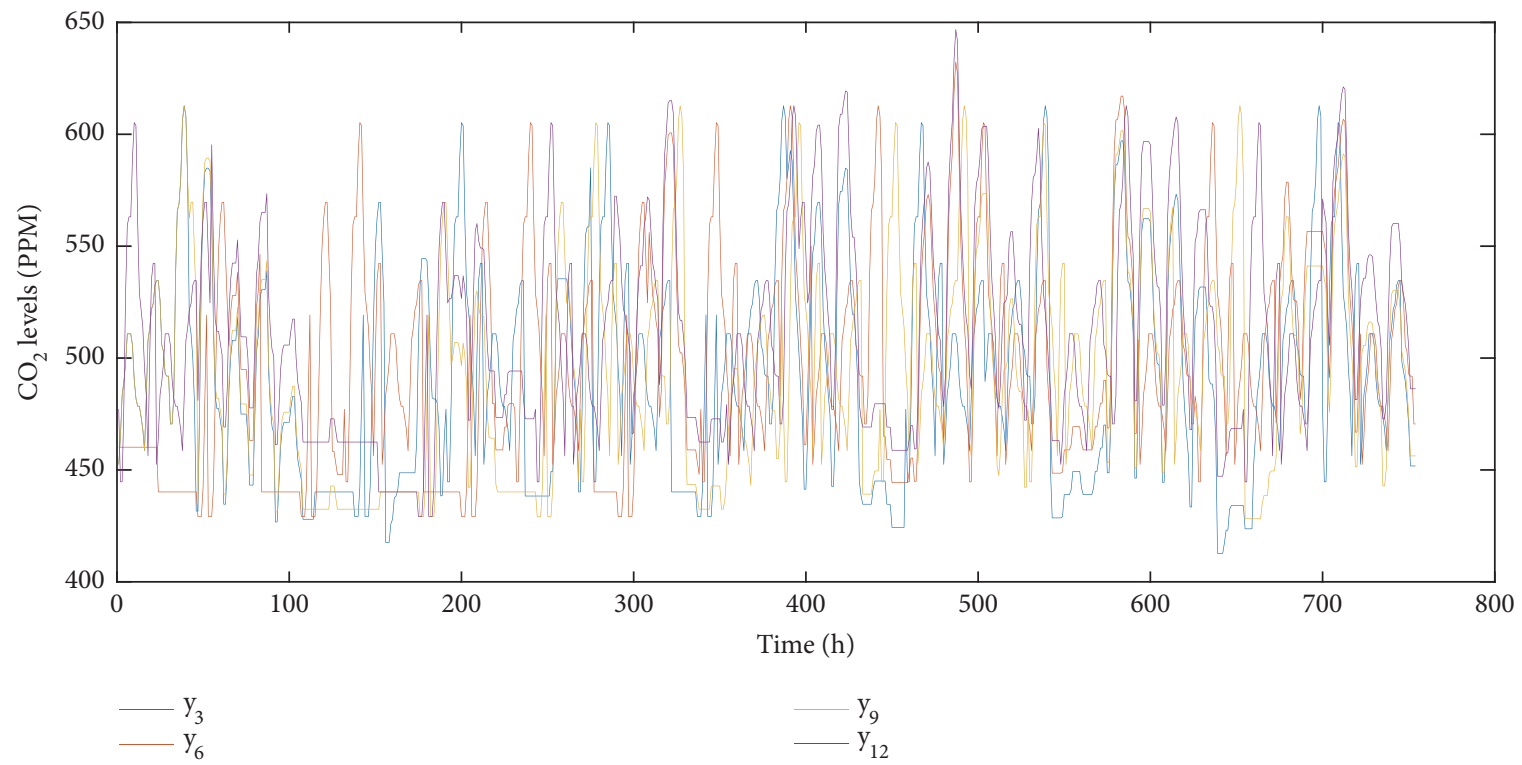

FIgURE 19: $\mathrm{A} \mathrm{CO}_{2}$ level of AHUs.

(5) Static Air Pressure $\left(\mathrm{P}_{\mathrm{s}}\right)\left(y_{2}, y_{5}, y_{8}, y_{11}\right)$. This data comes from two sensors: one for hot ducts and one for cold ducts. As illustrated in Figure 20, these outputs can be applied to the control of supply fan speed.

(6) Supply Fan Speed $\left(u_{2}, u_{5}, u_{8}, u_{11}\right)$. This data is derived from AHUs, the sensor. Figure 18 depicts the sensors measuring the fan speed of AHUs. The sample time $\left(T_{s}\right)$ for gathering the data is one hour, and the input signals are obtained in percentages.
System disturbances $(w)$ can occur with changes to wind speed/direction and outside temperature. These changes are recorded in the IDA-ICE software and the input/output signal data series organized through MATLAB. The ordering of the data is imperative before moving onto the next stage, which is system identification using the System Identification (SI) Toolbox. Every individual data set is cut in two: one-half represents estimation data, while the other half represents validation data. 


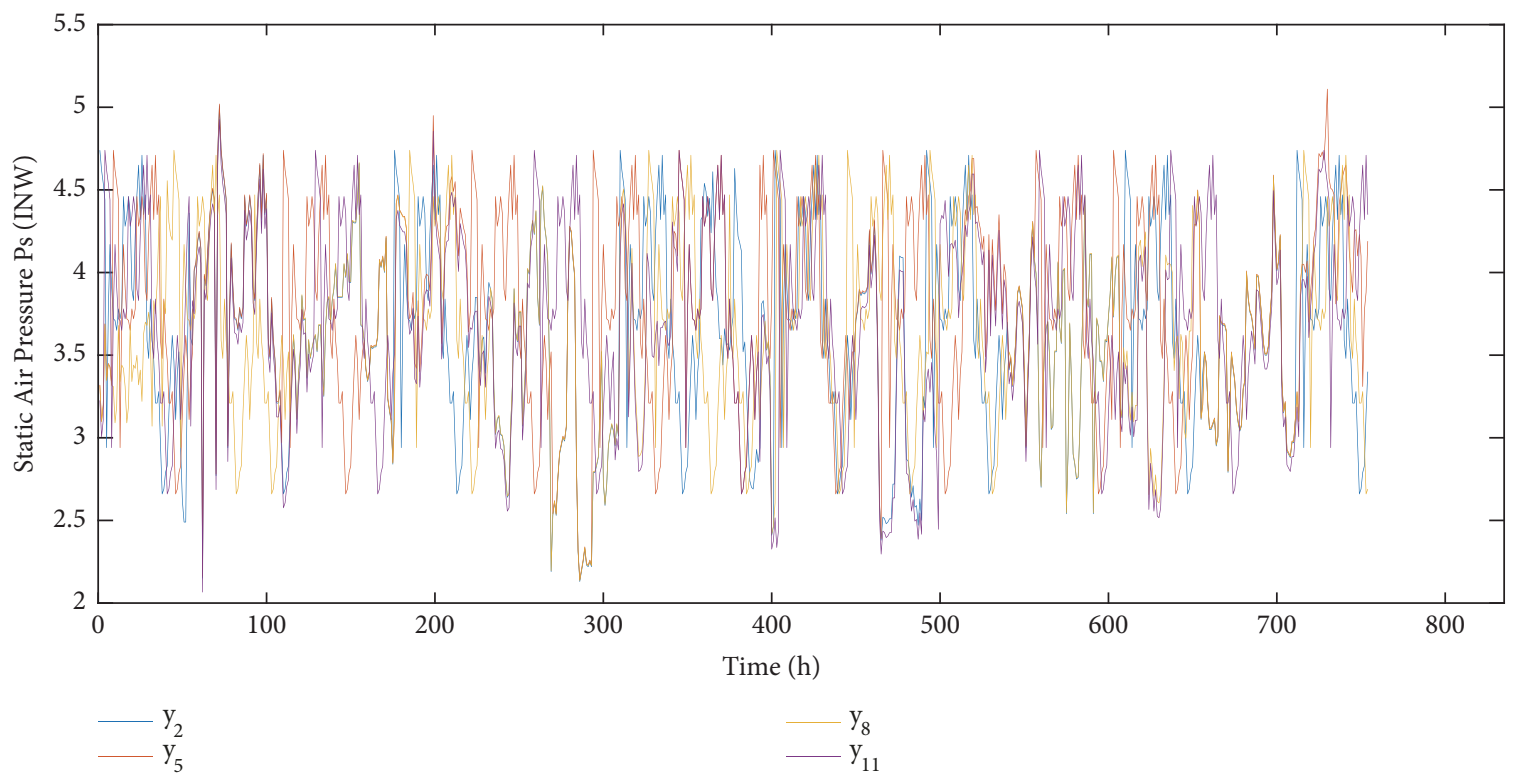

FIgURE 20: The static air pressure of AHUs.
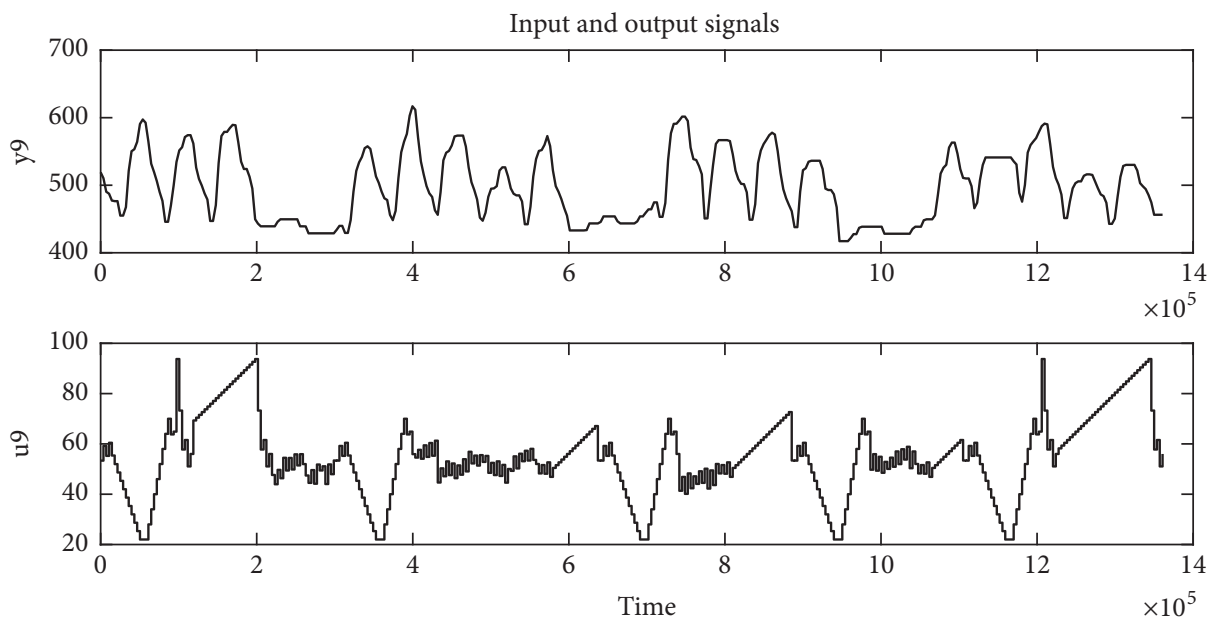

FIGURE 21: Input and output signals of $\mathrm{CO}_{2}$ level of $\mathrm{AHU}_{3}$.

Data from the first half (Data 1) are organized as input/output sets using MATLAB. The inputs are arranged into 12 columns, with every column relating to a specific input signal. Note that the number of rows is equal to the number of simulation period hours. Similarly, the outputs are also arranged into 12 columns, with every column relating to a specific output signal and the number of rows being equal to the number of input arrays. In these calculations, both the estimation and validation data have a 90-day time frame. Figures 21, 22, and 23 show some of the time plots of this data for estimation. The $\mathrm{CO}_{2}$ level of $\mathrm{AHU}_{3}$, static air pressure of $\mathrm{AHU}_{2}$ and zone temperature of $\mathrm{AHU}_{1}$ is shown. The output is the upper plot and the input is the lower plot.

Every state-space model is estimated in the SI Toolbox. The models undergo a comparison based on the degree of accuracy between the validation data sets' estimated and measured (i.e., real) outputs. In comparison, the estimated and real outputs are plotted for every model, after which a numerical value is allotted regarding the model's "fit." Using the SI Tool, the estimated outputs for numerous models are able to be plotted quickly and at the same time, with the model showing the highest value (i.e., the best "fit") deemed to have the greatest reliability. As an outcome of the process, we can obtain state-space models for Data 1 data groups and compare models across different seasons. For detrending the data, there are no alterations made to any relative differences among inputs and outputs.

Figure 24 shows the output of the model that follows the temperature of a zone in $\mathrm{AHU}_{1}$ with the same output as the real system. The agreement between these graphs can be seen as a percentage of the error. Ideally, this result is $57 \%$. Also, Figure 25 shows that the system performance percentage 

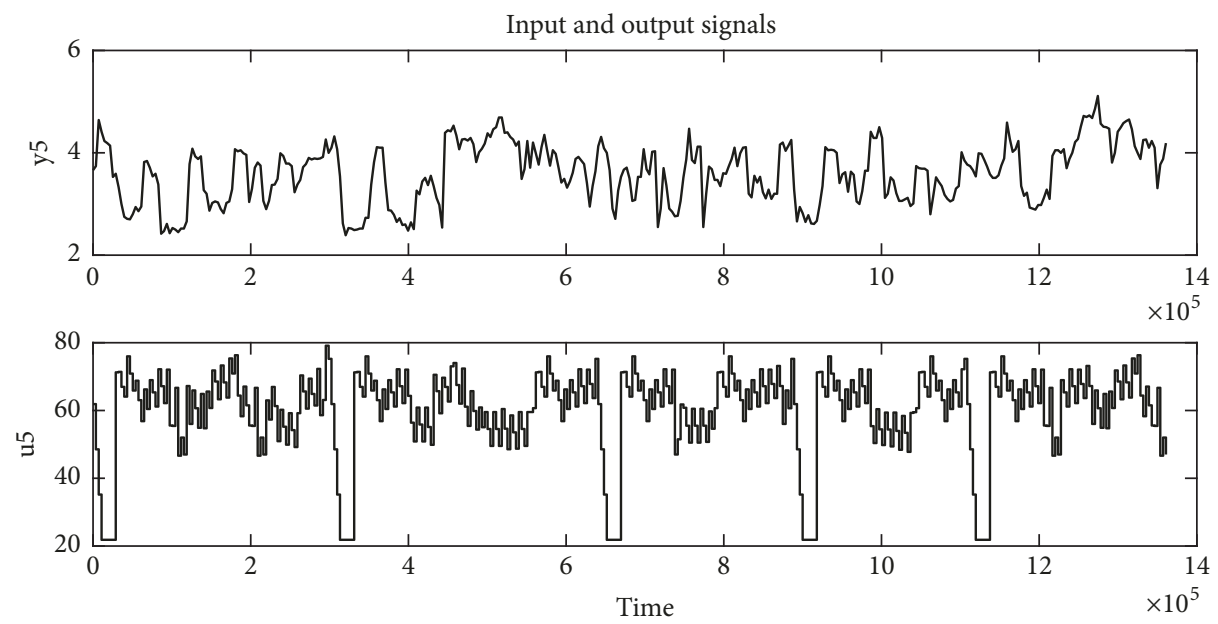

FIGURE 22: Input and output signals of the static air pressure of $\mathrm{AHU}_{2}$.
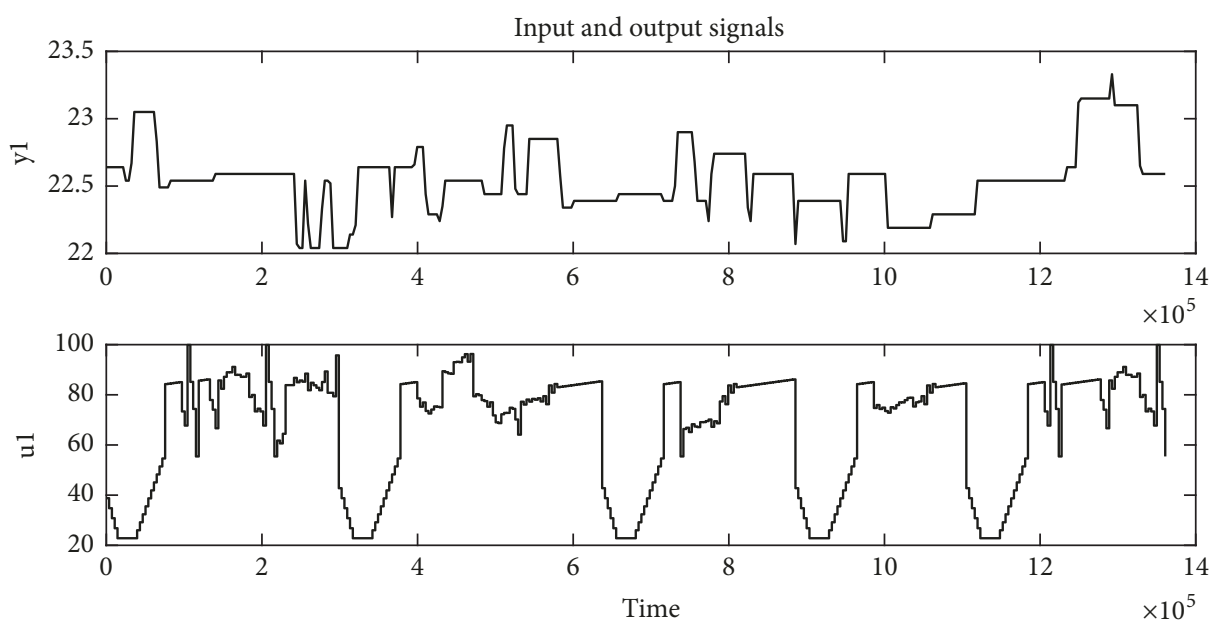

FIGURE 23: Input and output signals of zone temperature of AHU1.

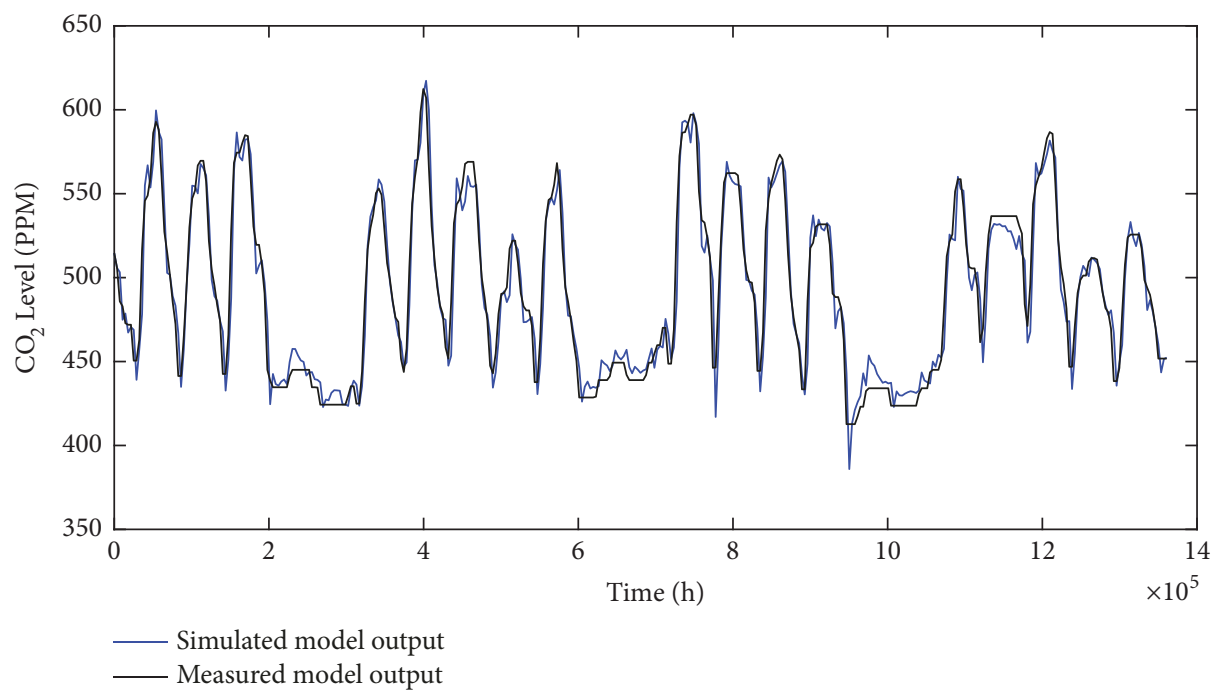

FIGURE 24: Validation of real measurements and outputs of CO2 level model fit $75 \%$. 


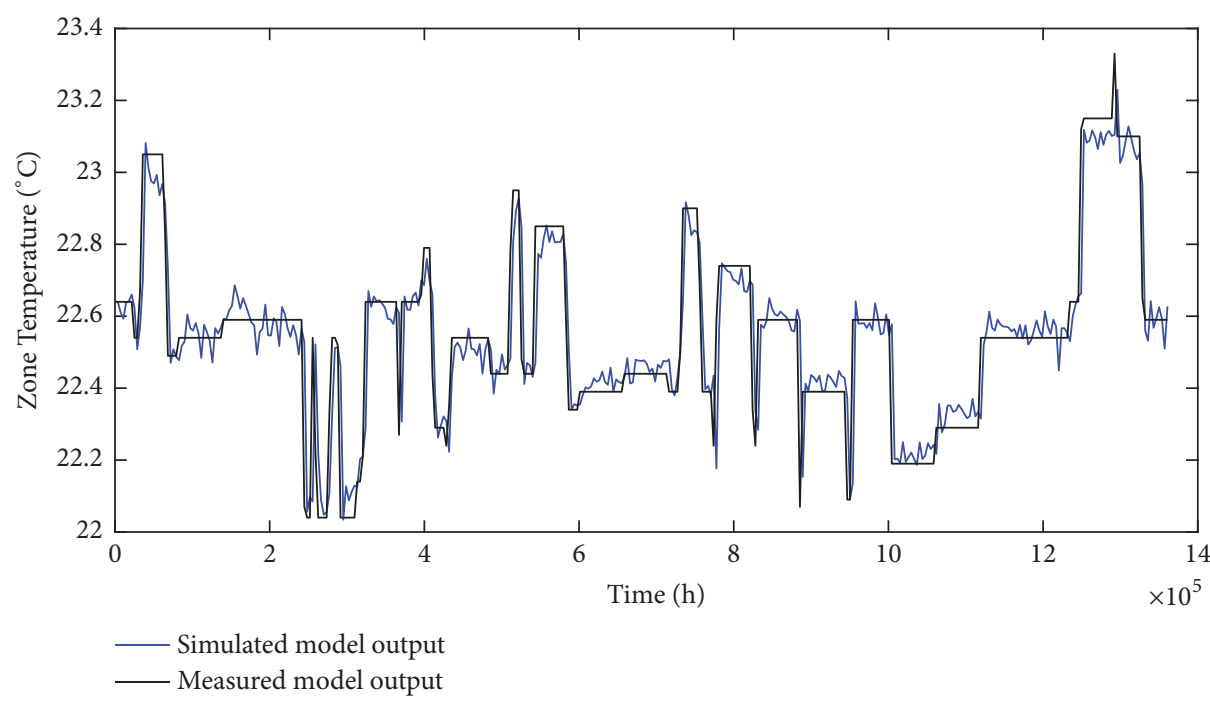

FIGURE 25: Validation of real measurements and outputs of zone temperature model fit $57 \%$.

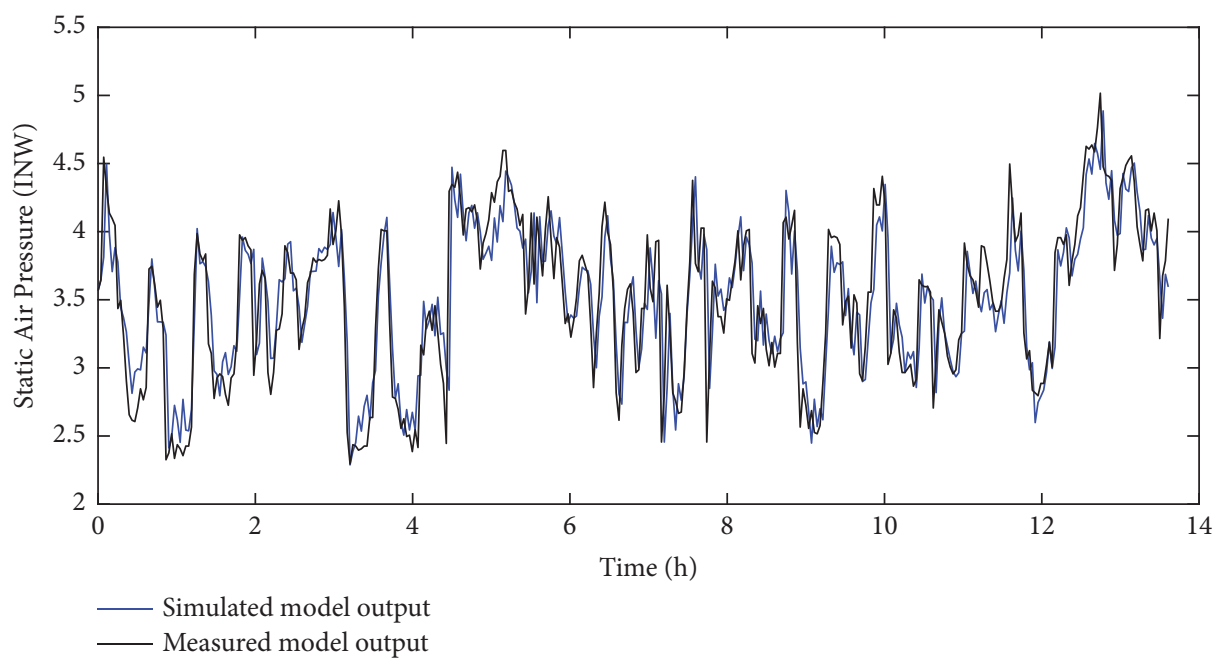

FIGURE 26: Validation of real measurements and outputs of the static air pressure model fit $49 \%$.

for the estimated model and the actual system of $\mathrm{CO}_{2}$ level of zone 3 in $\mathrm{AHU}_{3}$ was $75 \%$. Also, the percentage of the estimation model of the static air pressure the simulated or predicted model output is shown together with the measured validation data in Figure 26.

The part of the system data that the model could not describe is called the residuals [28-30]. They contain important information about the quality of the estimated model. The cross-correlation between residuals and the correct model does not exceed the confidence level [28]. If this is the case, the original model has captured the underlying properties of the system. The remaining autocorrelation indicates whether the error pattern is accurate. Standard process models do not evaluate the error model and unknown interference is not in the original model, thus the remaining runtime is not used for model verification. Figures 27, 28, and
29 show plots of the autocorrelation and cross-correlation of system responses to inputs. It is clear from the crosscorrelation diagram of these figures that the estimated model is very similar to the responses of the system to the inputs; the correlation curves lie between the dashed lines.

To determine model settings for the system, a linear parametric model can be estimated from a state-space structure. In general, the state-space model discrete-time settings generally feature the following structure:

$$
\begin{aligned}
X(t+T s) & =A x(t)+B u(t)+K e(t) \\
Y(t) & =C x(t)+D u(t)+e(t)
\end{aligned}
$$

where the $x(t)$ represents the states of the system and $y(t), u(t)$ and $e(t)$ represent the output, input and error. 
The $A, B, C, D$ and $K$ matrices contain the model parameters, and $T s$ is the sampling time of the system.

For modeling multi-input/multi-output (MIMO) systems, state-space models have been proven to be the most popular option, likely because the state-space method is relatively simple. For the system used in the present work (twelve inputs and twelve outputs), the discrete-time statespace model for order 12 (sampled as Ts $=3600 \mathrm{~s}$ ) and the $\mathrm{A}, \mathrm{C}$, and $\mathrm{K}$ matrices are as follows:

A

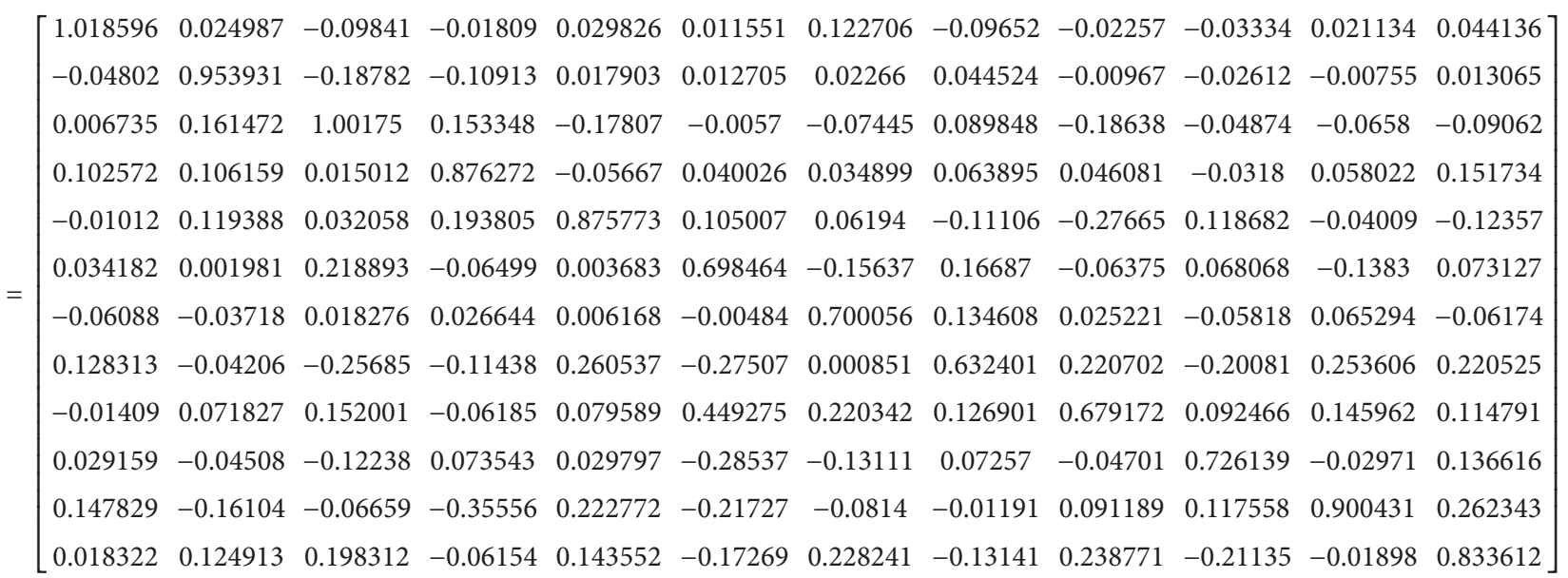

C

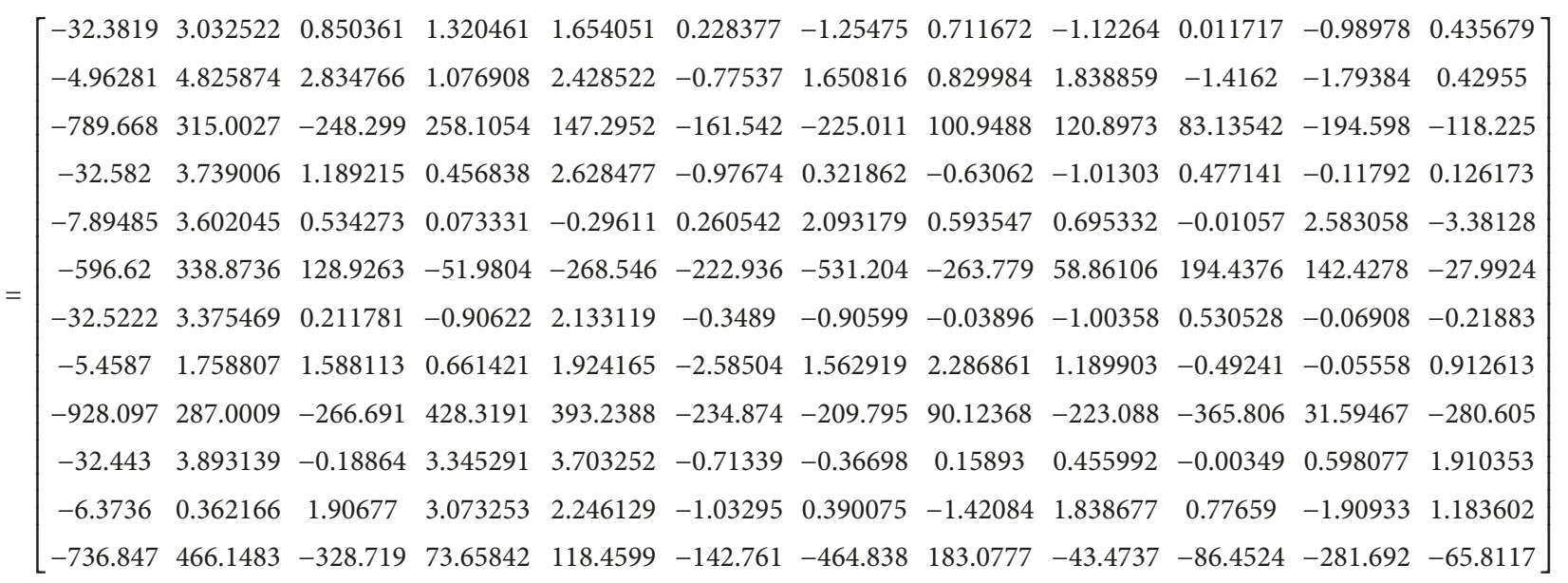

K

$=\left[\begin{array}{cccccccccccc}-0.02247 & 0.002415 & -0.00017 & 0.006293 & -0.00173 & 0 & -0.00404 & -0.00078 & -0.00012 & 0.006362 & 0.00369 & 0.000173 \\ -0.03766 & 0.008826 & 0.000201 & 0.019432 & 0.012113 & 0 & 0.006975 & -0.00743 & 0 & 0.012768 & -0.01539 & 0.000242 \\ 0.033593 & 0.016611 & 0 & 0.004704 & 0.002891 & 0.000146 & -0.01335 & -0.00477 & -0.00877 & -0.02582 & 0.004979 & -0.00043 \\ 0.03453 & -0.00396 & 0.000281 & -0.01639 & 0.002948 & 0.000201 & -0.05972 & 0.003692 & 0.000146 & 0.040423 & 0.001516 & 0.003516 \\ -0.03892 & 0.023262 & -0.00018 & 0.037843 & -0.00404 & -0.00028 & 0.00469 & -0.01357 & 0 & -0.01751 & 0.014066 & 0 \\ 0.051835 & 0.000717 & -0.00015 & -0.03922 & -0.00076 & -0.00837 & -0.00337 & -0.01172 & 0 & -0.00887 & 0.006588 & -0.00045 \\ -0.02582 & 0.005204 & 0.000455 & 0.030462 & 0.009431 & -0.00026 & 0.011997 & 0.002781 & 0.000145 & 0.00114 & -0.02152 & -0.0003 \\ -0.01015 & -0.01334 & 0 & -0.04976 & 0.014821 & -0.00084 & 0.001932 & 0.016727 & 0 & 0.036388 & -0.02471 & 0 \\ -0.01445 & 0.018199 & 0.000477 & -0.02753 & 0.006731 & 0.000156 & 0.001845 & -0.00527 & -0.00022 & 0.030758 & 0.010523 & 0.000299 \\ -0.03034 & -0.00941 & 0.000446 & 0.010668 & 0.006548 & 0 & 0.021502 & 0.01097 & -0.00015 & -0.01222 & -0.0214 & -0.00045 \\ -0.01857 & -0.02641 & 0 & -0.04546 & 0.014413 & -0.00011 & 0.01149 & 0.013894 & 0.000132 & 0.034855 & -0.01938 & -0.00053 \\ 0.01201 & 0.001892 & -0.00049 & 0.008802 & -0.02405 & 0 & -0.06658 & 0.00417 & -0.00037 & 0.067378 & 0.02137 & 0.000465\end{array}\right]$



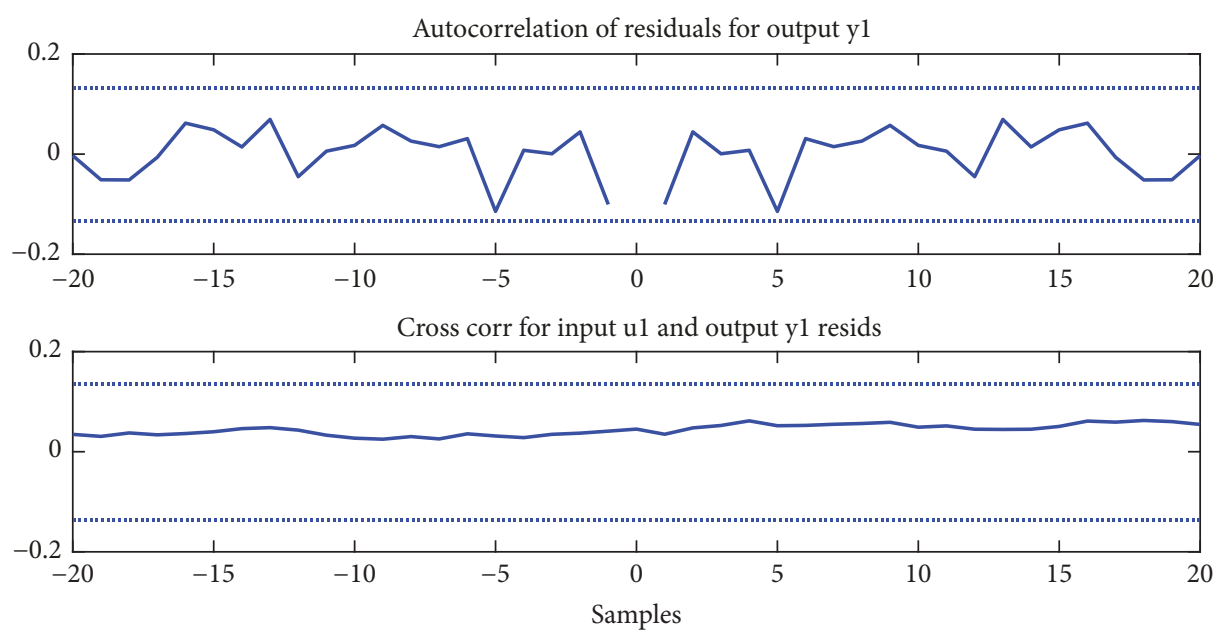

FIGURE 27: Autocorrelation yl and cross-correlation of system responses ul \& yl.
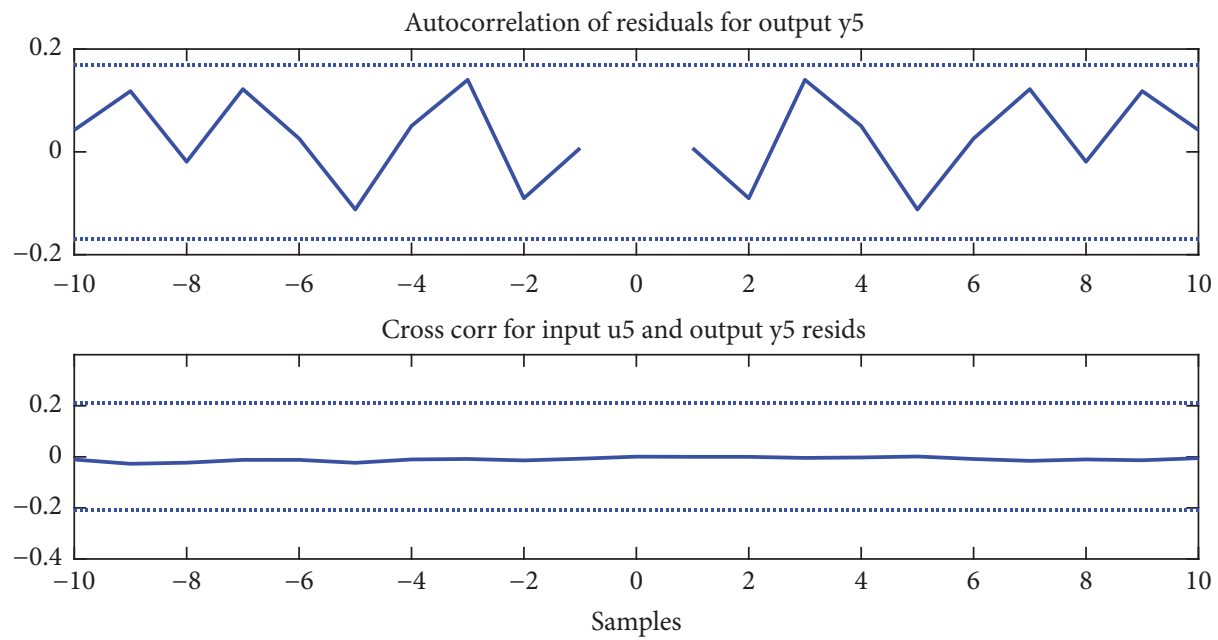

FIGURE 28: Autocorrelation y5 and cross-correlation of system responses u5 \& y5.
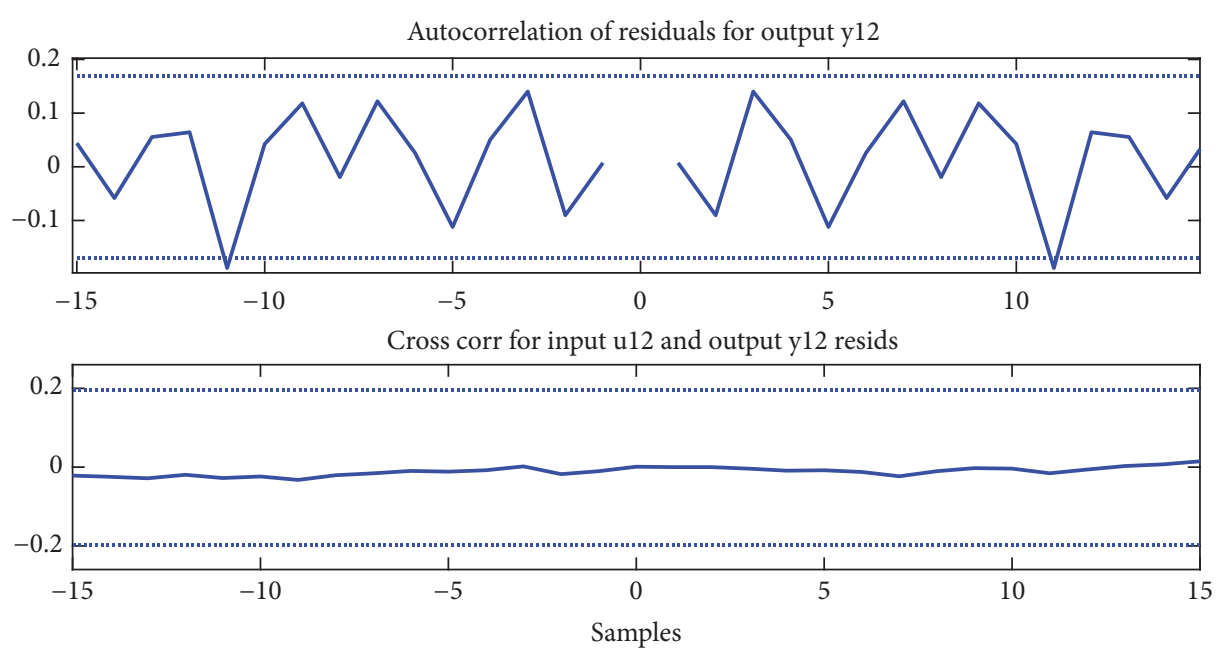

FIGURE 29: Autocorrelation y12 and cross-correlation of system responses u12 \& y12. 


\section{Conclusions}

In this paper, the S. J. Carew building was modeled using the IDA-ICE program using all details of HVAC system and instructions of the building. This model provides good approximations comparing the consumption of hot water and electricity with the measured data for a full year (2016). It also compares the average of the outside temperature of the weather file of IDA-ICE program and the measured data. All system inputs and outputs were selected, and a linear statespace model was identified describing the thermal response of the system. The dynamic model is required to design and test system controllers before actual implementation. The model was derived using MATLAB's System Identification (SI) Toolbox. The model has twelve state variables, twelve inputs, and twelve outputs. The model responses when compared with actual data are within the allowed range. Validation data and autocorrelation function for the residuals as well as the cross-correlation function between input and residuals are computed and presented.

\section{Data Availability}

The data used to support the findings of this study are available from the corresponding author upon request.

\section{Conflicts of Interest}

The authors declare that they have no conflicts of interest.

\section{Acknowledgments}

This work is funded by the Ministry of Higher Education of Libyan Government, which is managed by CBIE in Canada. Also, the authors thank the Honeywell Office and Department of Facilities Management at Memorial University for providing them with structure details of the building and access to Honeywell software of the HVAC system.

\section{References}

[1] E. Abel, L. E. Per-Erik Nilsson, L. J. Per Fahlén et al., "Achieving the desired indoor climate-energy efficiency aspects of system design," Studentlitteratur, 2003.

[2] H. Awbi, Ventilation of Buildings, Spon Press, 2003.

[3] H. Goodfellow, Industrial Ventilation Design Guidebook, Elsevier, 2001.

[4] American Society of Heating Refrigerating and AirConditioning Engineers, ASHRAE Handbook, Fundamentals, 2009.

[5] A. Abdo-Allah, T. Iqbal, and K. Pope, "Modeling, analysis, and state feedback control design of a multizone HVAC system," Journal of Energy, vol. 2018, Article ID 4303580, 11 pages, 2018.

[6] J. C.-M. Yiu and S. Wang, "Multiple ARMAX modeling scheme for forecasting air conditioning system performance," Energy Conversion and Management, vol. 48, no. 8, pp. 2276-2285, 2007.

[7] G. Mustafaraj, J. Chen, and G. Lowry, "Development of room temperature and relative humidity linear parametric models for an open office using BMS data," Energy and Buildings, vol. 42, no. 3, pp. 348-356, 2010.

[8] G. Mustafaraj, G. Lowry, and J. Chen, "Prediction of room temperature and relative humidity by autoregressive linear and nonlinear neural network models for an open office," Energy and Buildings, vol. 43, no. 6, pp. 1452-1460, 2011.

[9] A. Rabl, "Parameter estimation in buildings: Methods for dynamic analysis of measured energy use," Journal of Solar Energy Engineering, vol. 110, no. 1, pp. 52-66, 1988.

[10] R. C. Sonderegger, Dynamic models of house heating, based on equivalent thermal parameters [Ph.D. thesis], Princeton Univ., NJ, USA, 1978.

[11] H. Boyer, J. P. Chabriat, B. Grondin-Perez, C. Tourrand, and J. Brau, "Thermal building simulation and computer generation of nodal models," Building and Environment, vol. 31, no. 3, pp. 207-214, 1996.

[12] K. K. Andersen, H. Madsen, and L. H. Hansen, "Modelling the heat dynamics of a building using stochastic differential equations," Energy and Buildings, vol. 31, no. 1, pp. 13-24, 2000.

[13] M. J. Jiménez, H. Madsen, J. J. Bloem, and B. Dammann, "Estimation of non-linear continuous time models for the heat exchange dynamics of building integrated photovoltaic modules," Energy and Buildings, vol. 40, no. 2, pp. 157-167, 2008.

[14] H. Madsen and J. Holst, "Estimation of continuous-time models for the heat dynamics of a building," Energy and Buildings, vol. 22, no. 1, pp. 67-79, 1995.

[15] L. Mei, D. Infield, U. Eicker, and V. Fux, "Thermal modelling of a building with an integrated ventilated PV façade," Energy and Buildings, vol. 35, no. 6, pp. 605-617, 2003.

[16] Y. Jeong and F. Haghighat, "Modelling of a hybrid-ventilated building using ESP-r," International Journal of Ventilation, vol. 1, no. 2, pp. 127-139, 2016.

[17] J. Jokisalo, J. Kurnitski, M. Korpi, T. Kalamees, and J. Vinha, "Building leakage, infiltration, and energy performance analyses for Finnish detached houses," Building and Environment, vol. 44, no. 2, pp. 377-387, 2009.

[18] M. Stadler, R. Firestone, D. Curtil, and C. Marnay, "On-site generation simulation with EnergyPlus for commercial buildings, ACEEE summer study on energy efficiency in buildings," in PANEL 3 - Commercial Buildings: Technologies, Design, Performance Analysis, \& Industrial Trends, Pacific Grove, California, USA, 2006.

[19] EQUA Simulation AB, IDA Indoor Climate and Energy Version 4.7, 2010, http://www.equa.se/en/ida-ice.

[20] P. Sahlin, L. Eriksson, P. Grozman, H. Johnsson, A. Shapovalov, and M. Vuolle, "Whole-building simulation with symbolic DAE equations and general purpose solvers," Building and Environment, vol. 39, no. 8, pp. 949-958, 2004.

[21] P. Sahlin, L. Eriksson, P. Grozman, H. Johnsson, A. Shapovalov, and M. Vuolle, "Equation-based building simulation make it? Experiences from the introduction of IDA indoor climate and energy," in Proceedings of the 8th International (IBPSA) International Building Performance Simulation Association Conference, vol. 39, pp. 949-958, Eindhoven, The Netherlands, August 2003.

[22] A. Abdo-Allah, T. Iqbal, and K. Pope, "Modeling and analysis of an HVAC system for the S.J. carew building at memorial university," in Proceedings of the 30th IEEE Canadian Conference on Electrical and Computer Engineering, CCECE 2017, pp. 1-4, IEEE, Windsor, Canada, May 2017.

[23] A. Abdo-Allah, T. Iqbal, and K. Pope, "Modeling, analysis, and design of a fuzzy logic controller for an ahu in the s.j. carew 
building at memorial university," Journal of Energy, vol. 2018, Article ID 4540387, 11 pages, 2018.

[24] L. Ljung, System Identification: Theory for the User, PrenticeHall, USA, 2006.

[25] L. Raillon and C. Ghiaus, "Study of error propagation in the transformations of dynamic thermal models of buildings," Journal of Control Science and Engineering, vol. 2017, Article ID 5636145, 15 pages, 2017.

[26] R. H. Chintala and B. P. Rasmussen, "Automated multi-zone linear parametric black box modeling approach for building HVAC systems," in Proceedings of the ASME 2015 Dynamic Systems and Control Conference, p. V002T29A004, American Society of Mechanical Engineers, USA, 2015.

[27] Z. Afroz, G. M. Shafiullah, T. Urmee, and G. Higgins, "Modeling techniques used in building HVAC control systems: A review," Renewable \& Sustainable Energy Reviews, vol. 83, pp. 64-84, 2018.

[28] L. Ljung, Q. Zhang, P. Lindskog, A. Iouditski, and R. Singh, "An integrated system identification toolbox for linear and nonlinear models," IFAC Proceedings Volumes, vol. 39, no. 1, pp. 931936, 2006.

[29] F. Scotton, L. Huang, S. A. Ahmadi, and B. Wahlberg, "Physicsbased modeling and identification for HVAC systems?" in Proceedings of the 12th European Control Conference (ECC '13), pp. 1404-1409, IEEE, July 2013.

[30] A. Barkley and E. Santi, "Improved online identification of a DC-DC converter and its control loop gain using crosscorrelation methods," IEEE Transactions on Power Electronics, vol. 24, no. 8, pp. 2021-2031, 2009. 

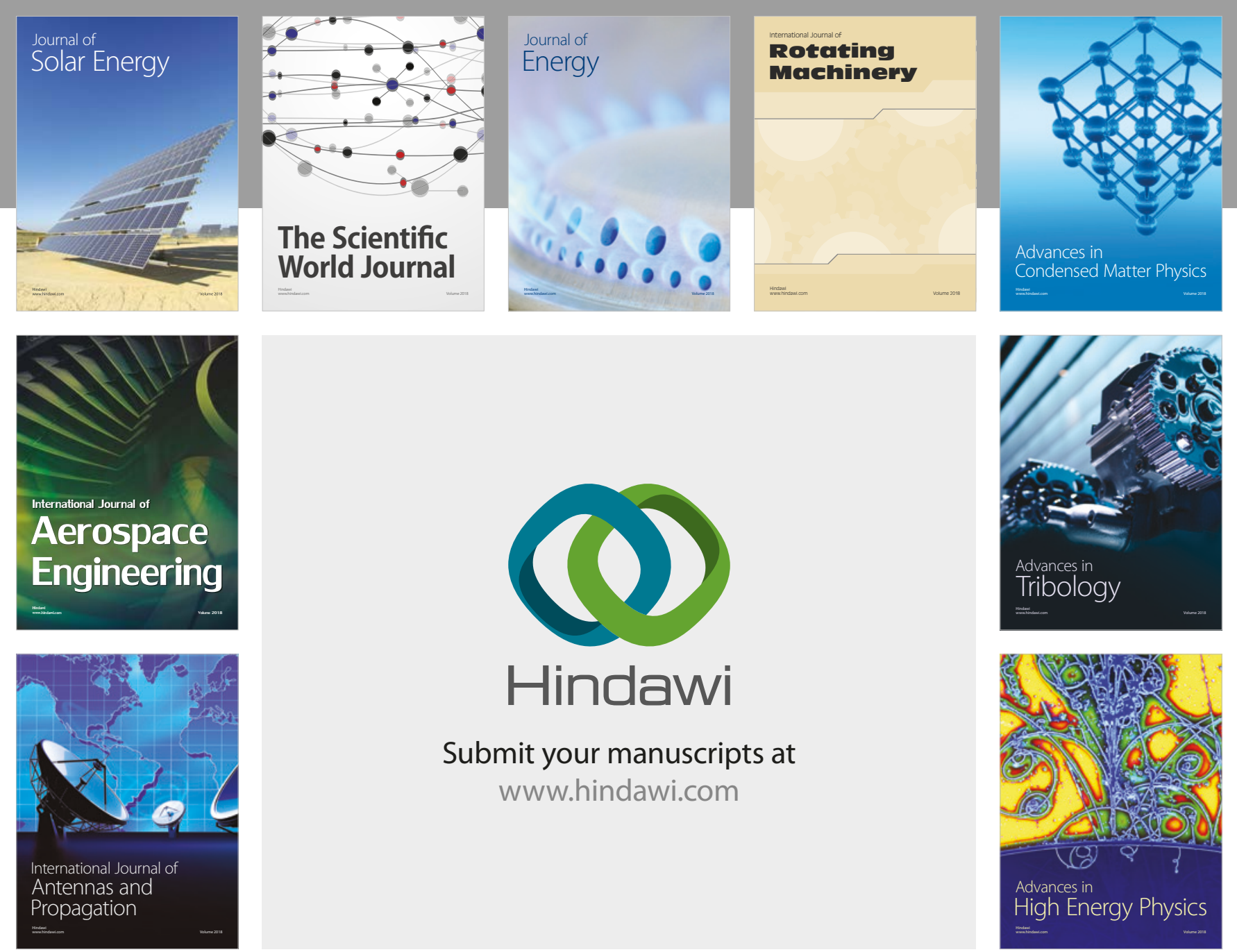

Submit your manuscripts at

www.hindawi.com
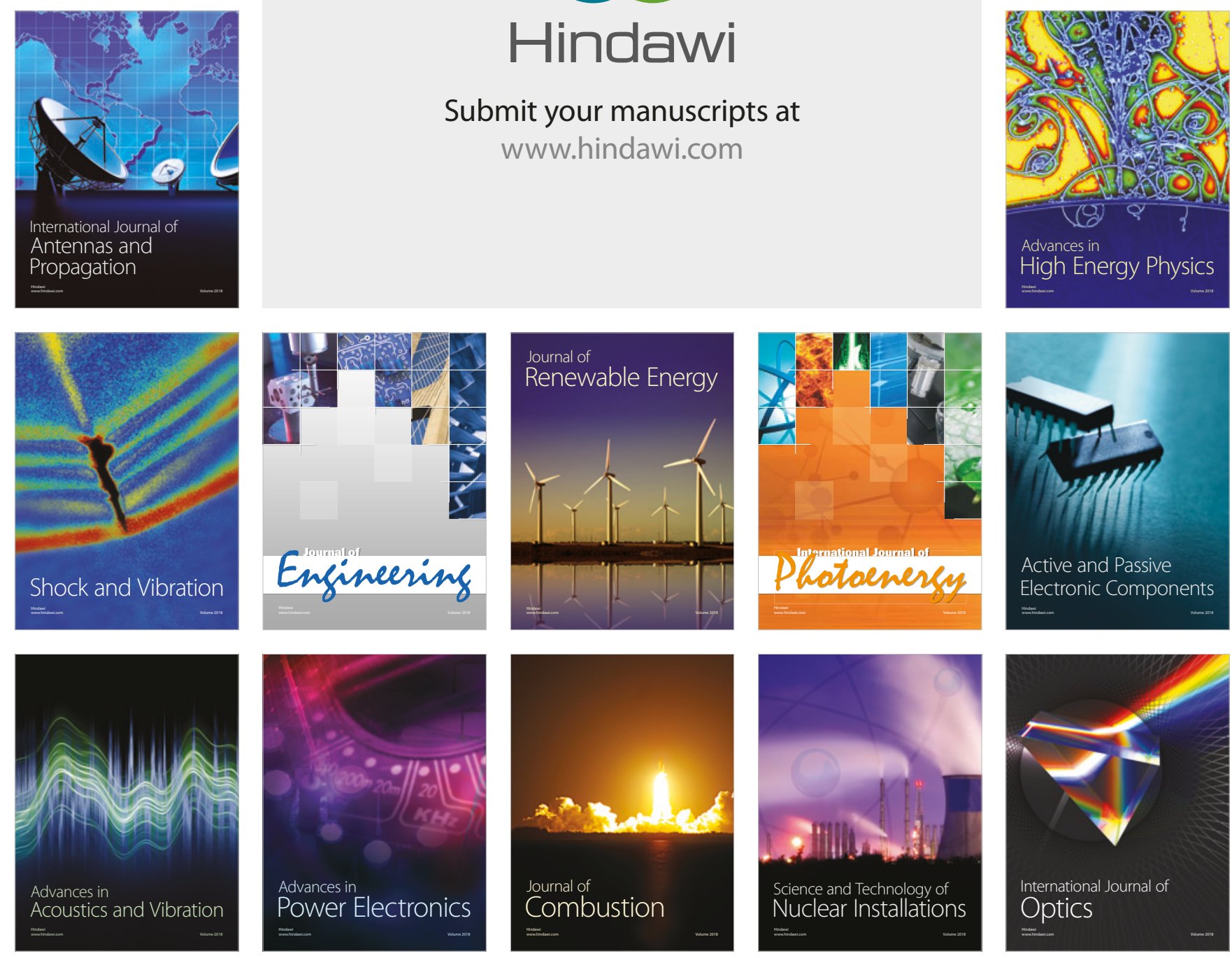